\title{
LABTUR: una contribución metodológica a las prácticas de co- creación del espacio público
}

\author{
Ana Carolina Cardoso ${ }^{1} \mid$ Alexandra Paio ${ }^{1}$ \\ Recibido: 30-11-2020 | en su versión final: 17-06-2021
}

Resumen

\begin{abstract}
La ciudad ha sido escenario de debates en las últimas décadas, fruto de la creciente urbanización y la consecuente complejidad de los problemas urbanos, que imponen profundos cambios en la forma de concebir, producir y gestionar el espacio urbano. Los laboratorios urbanos emergen como entornos experimentales e de aprendizaje colaborativo, explorando nuevos caminos para la producción compartida de conocimiento y soluciones a los problemas urbanos actuales, promoviendo la inteligencia colectiva basada en experimentos locales probados dentro de una cultura específica y un contexto situado. Partiendo de la idea de un laboratorio urbano experimental, esta investigación tiene como objetivo presentar la primera edición de LABTUR, desarrollada en el programa TUR: Co-creating Public Spaces, un proyecto de investigación-acción llevado a cabo en un contexto académico, en colaboración con el Ayuntamiento de Cascais, en Portugal. El artículo presenta los resultados de LABTUR y discute el aprendizaje basado en las dinámicas de co-creación, contribuyendo a la definición de una metodología colaborativa que promueva el diseño de un espacio público más sostenible e inclusivo.
\end{abstract}

Palabras clave: espacio urbano; laboratorio experimental urbano; co-creación; metodologías colaborativas

Citación

Cardoso, A y Paio, A. (2021). LABTUR: Una contribución metodológica a las prácticas de cocreación del espacio público. ACE: Architecture. City and Environment. 16(46), 9893. DOI: http://dx.doi.org/10.5821/ace.16.46.9893

\section{LABTUR: A Methodological Contribution to the Practices of Co-creation of Public Space}

Abstract

\begin{abstract}
The city has been the scene of debates in recent decades, the result of growing urbanization and the consequent complexity of urban problems, which impose profound changes in the way of conceiving, producing and managing urban space. Urban laboratories emerge as collaborative learning and experimental environments, exploring new paths for the shared production of knowledge and solutions to current urban problems, promoting collective intelligence based on local experiments tested within a specific culture and situated context. Starting from the idea of an experimental urban laboratory, this research aims to present the first edition of LABTUR, developed in the program TUR: Co-creating Public Spaces, an action-research project carried out in an academic context, in collaboration with the City Council of Cascais, in Portugal. The article presents the results of LABTUR and discusses learning based on co-creation dynamics, contributing to the definition of a collaborative methodology that promotes the design of a more sustainable and inclusive public space.
\end{abstract}

Keywords: urban space; experimental urban laboratory; co-creation; collaborative methodologies

${ }^{1}$ Arquitecta, Maestra en Arquitectura y candidata a Doctor en Arquitectura de los territorios metropolitanos contemporáneos en Iscte-Instituto Universitario de Lisboa, Portugal (ORCiD: 0000-0002-7477-6878), ${ }^{2}$ Profesora titular en Iscte-Instituto Universitario de Lisboa, Portugal (ORCiD: 0000-0002-4144-8499). Correo de contacto: carolina.stc@gmail.com 


\section{Introducción}

"Cities are an immense laboratory of trial and error, failure and success, in city building and city design. This is the laboratory in which city planning should have been learning and forming and testing theories." (Jacobs, 1960 en Gehl, 2013: pág. 78)

La creciente urbanización y la consecuente complejidad de los problemas urbanos que afectan a las ciudades y sus periferias, imponen cambios profundos en la forma en que se concibe, produce y gestiona el espacio público, considerando no solo su carácter físico, sino también asumiendo factores sociales, económicos y ambientales como parte de un proceso integrado que genera cambios positivos (DGT, 2020; ONU, 2016).

La "revolución urbana" iniciada en el siglo XX (Lefebvre, 2002[1970]; Borja, 2011) trae consigo varias contradicciones sobre el "derecho a la ciudad" que defiende Lefebvre (1968). Desde las décadas de 1960 y 1970, la planificación racionalista, con un enfoque de arriba hacia abajo, ha sido cuestionada, ya que no ha proporcionado los cambios sistémicos fundamentales para mejorar la calidad de vida en las áreas urbanas, con una capacidad limitada para responder a los problemas (Friedmann, 1987, 1993; Gehl 2015; Jacobs 1991) como segregación socioespacial. Según Teresa Salgueiro (1998), a partir de los años 70, "el aumento de la diversidad y la fragmentación de la estructura social encuentran un eco en la organización urbana que tiende a evolucionar hacia una mayor fragmentación" Salgueiro (1998, p.41). Así, el debate sobre la ciudad como espacio de producción social (Guerra, 2012; Awan et al, 2011; Lefebvre, 1991; Petrescu et al, 2017) ha crecido en los últimos años. Al mismo tiempo que aumenta la presión sobre las agendas globales por una mayor responsabilidad ambiental y la adopción de procesos más participativos en la construcción de ciudades (DGT, 2020; ONU, 2016; Unión Europea, 2021), la esfera digital ha mejorado la capacidad de las personas para autoorganizarse (Castells, 2010; Foth et al, 2015), multiplicando las prácticas colaborativas que buscan asegurar una mejor calidad de vida urbana, especialmente en territorios de exclusión y asentamientos informales (UN-HABITAT, 2016), donde el crecimiento urbano desordenado han afectado la calidad del espacio público y la vida pública, que son fundamentales para el bienestar de una comunidad.

Temas significativos de estas prácticas están relacionados con el potencial de la escala de proximidad (Hamdi, 2004) y la unión de diferentes tipos de conocimiento, en la búsqueda de soluciones que respondan a los complejos y multidimensionales problemas de los territorios. Según Guerra (2012) "las soluciones no son solo en una disciplina sino en una mirada compleja y sistémica que integra académicos, técnicos de campo y poblaciones”. La creación conjunta de soluciones para una ciudad más inclusiva y sostenible requiere la colaboración de múltiples partes interesadas y un equilibrio de intereses entre las diferentes atores (Concilio, et al, 2016; Ermacora et al, 2016; Healey, 1997; Sanders, 2008). Ezio Manzini (2015) también destaca que, aunque todos tienen recursos de diseño, estos recursos deben nutrirse para que desempeñen un papel activo y significativo en la promoción del cambio social.

Muchas de estas prácticas funcionan en los territorios en forma de laboratorio urbano, de carácter temporal e inmersivo. Según Juan Freire (2020) wicked problems (problemas retorcidos) "plantean retos metodológicos dado que, al no estar definidos por completo, solo se pueden comprender mediante la inmersión y por tanto solo cuando nos afectan porque somos parte activa del propio proceso" (Freire, 2020, pág. 5). Estos laboratorios, identificados como entornos multi-actor, abiertos al diálogo, al intercambio y al conflicto, buscan experimentar nuevos métodos para la producción compartida de conocimiento, dando lugar a posibles caminos para la co-creación de soluciones, a través de la promoción de la inteligencia colectiva basada en experimentos locales probados dentro de una cultura específica y un contexto situado (Oliván, et al. 2018; SEGIB, 2014; Concílio, 2016;

ACE, 16 (46) CC BY-ND 3.0 ES | UPC Barcelona, España | LABTUR: Una contribución metodológica a las prácticas de co-creación del espacio público. DOI: http://dx.doi.org/10.5821/ace.16.46.9893 
Lafuente et al., 2008,2013; Evans et al, 2016). Al mismo tiempo, tienen un alcance global potenciado por la expansión de la conectividad de la red, los principios de colaboración y la ética participativa de la cultura en línea (De Lange, et al, 2016; Sá, 2015; Foth et al, 2015) y que han promovido el crecimiento de una cultura de compartir, en la que diferentes actores pueden colaborar en soluciones, desde el diseño hasta la materialización (Claudel, 2016; Gershenfeld, 2015). Este escenario es un campo fértil para la reflexión sobre un cambio de paradigma en la forma de actuar en el proceso de construcción de ciudades.

El laboratorio "nos sitúa necesariamente en la dinámica de producción colectiva e innovadora de la realidad, y no en la lógica misma del registro y análisis. El laboratorio, por tanto, se refiere al diseño, la experimentación y la colaboración" (Fonseca A., 2012 en Fonseca, 2014, pag.28). Este enfoque de co-creación experimental introduce la idea de la ciudad como laboratorio, que pretendemos explorar en este artículo en el contexto de territorios de génesis ilegal.

Partiendo del concepto de laboratorio urbano experimental, esta investigación tiene como objetivo presentar la experiencia del laboratorio piloto LABTUR desarrollado en el marco de la 1a edición de la escuela de verano TUR'19 - Technopolitics in Urban Regeneration: Co-creating Public Spaces, un proyecto universitario de extensión coordinado por ISCTE-Instituto Universitário de Lisboa, en colaboración con el Ayuntamiento de Cascais, Portugal.

El objetivo de este trabajo es reflexionar sobre el proceso de aprendizaje y los resultados de LABTUR'19 y comprender su contribución a prácticas más colaborativas e inclusivas en la co-creación local del espacio público. Se pretende contribuir a discutir los desarrollos futuros y los próximos pasos hacia una colaboración más profunda entre la Academia, el Gobierno y la población local, buscando presentar las dimensiones estratégicas de los diversos actores involucrados en relación a los objetivos del proyecto.

\subsection{Co-creación experimental local}

Según Harvey (2012) "El derecho a la ciudad es mucho más que la libertad individual de acceder a los recursos urbanos: se trata del derecho a cambiarnos a nosotros mismos cambiando la ciudad. Es, además, un derecho común antes que individual, ya que esta transformación depende inevitablemente del ejercicio de un poder colectivo para remodelar los procesos de urbanización" Harvey (2012, p.23). El poder colectivo se relaciona con el concepto de co-creación definido por Sanders y Stappers (2008) como "any act of collective creativity, i.e. creativity that is shared by two or more people". En un sentido muy amplio, co-crear es hacer juntos lo que puede ir "from the physical to the metaphysical and from the material to the spiritual" (Sanders y Stappers, 2008, pág. 6).

El prefijo "co-" puede indicar el carácter colaborativo, cooperativo, colectivo o solidario (Alexiou y Zamenopoulos 2018) al participar en una determinada actividad. Considerando el objetivo de esta investigación de contribuir a las prácticas de co-creación del espacio público, la primera dirección parece más adecuada para explorar, lo que significa que un grupo de personas trabaja y aprende juntas para desarrollar un proyecto que responda a un desafío común, y puede crear mejores visiones del futuro. (Puerari, et al, 2018; Zamenopoulos y Alexiou, 2018).

A mediados del siglo XX, en el contexto de la arquitectura y el urbanismo, un grupo de profesionales empezó a defender la participación de la ciudadanía en la co-creación de sus ciudades, dando lugar a términos como 'arquitectura participativa', 'planificación colaborativa' o 'diseño participativo' (Zamenopoulos y Alexiou, 2018, Pasty, 1993, Friedmann, 1993, De Carlo, 1980). Sin embargo, más recientemente se ha explorado con mayor profundidad el concepto de co-creación en las áreas más

ACE, 16 (46) CC BY-ND 3.0 ES | UPC Barcelona, España | LABTUR: Una contribución metodológica a las prácticas 3 de co-creación del espacio público. DOI: http://dx.doi.org/10.5821/ace.16.46.9893 
diversas, partiendo de la creencia de facilitar procesos de cambio más efectivos en contextos urbanos cada vez más complejos (Puerari, et al, 2018). Según John Friedman (1993), la co-creación se ha convertido en un objetivo a alcanzar, no en un método en sí mismo. Desde su perspectiva, la planificación requiere conectar "forms [specialized and experimental] of knowledge with forms of action in the public domain" (1993, pag.482) a una escala donde ocurre la vida cotidiana de las personas y donde surgen problemas específicos del lugar, a nivel de la calle, barrio o ciudad (Chase et al, 2008).

En esta lógica, el ejercicio de dibujar la ciudad a través de la experimentación local y multiactor funciona "como un instrumento para problematizar los problemas contemporáneos" (Fonseca, 2014, p.28). La experimentación es una herramienta para aprender y producir nuevos conocimientos, ya que conduce a procesos de error y el error conduce a procesos de aprendizaje (Lafuente et al, 2016), un escenario muy difícil de observar en las instituciones públicas.

Volviendo a la idea del laboratorio, muchos autores afirman que el laboratorio crea la realidad, por lo que "el laboratorio [puede] ser visto como un lugar de producción y reproducción de la realidad" (Lafuente, 2008). En la visión de la ciudad como un laboratorio y un entorno de experimentación, los procesos de colaboración (un conjunto de métodos y herramientas analógicos y digitales) se reformulan, adaptan y prueban constantemente, desafiando a los responsables políticos, planificadores, ciudadanos e investigadores a trabajar juntos por un bien común, en un contexto específico, sujeto a la acción local (Concilio, 2016). Los resultados pueden variar desde sustratos tangibles hasta formas intangibles que componen el espacio urbano. Así, según afirma Friedmann (1993, pág. 482) "solution should be as complex as the problem it proposes to solve".

\section{TUR'19: Co-creating Public Spaces}

TUR ${ }^{1}$ es un proyecto de investigación-acción que tuvo su primera edición en 2019 y que tiene como objetivo ampliar el campo de las prácticas colaborativas y espacios establecidos para la producción compartida de conocimiento y que permite formas más horizontales de interacción entre diferentes actores en la construcción de soluciones conjuntas para la problemas urbanos. Con el fin de integrar el conocimiento científico, técnico y local con preocupaciones de diseño estratégico, el proyecto propone conectar a estudiantes de arquitectura, investigadores, ciudadanos y el municipio en un enfoque de aprendizaje colaborativo, para experimentar métodos más inclusivos de co-creación del espacio público.

La metodología de la investigación involucró los siguientes pasos: (1) Estudio del estado del arte sobre prácticas colaborativas de co-creación del espacio público, a partir de la colaboración científica entre investigadoras que comparten líneas temáticas complementarias; (2) Definición de estudios de casos en el ámbito de la colaboración entre ISCTE - Instituto Universitario de Lisboa y el Ayuntamiento de Cascais, Portugal; (3) Convocatoria de artículos para la conferencia internacional, con el objetivo de promover el intercambio de prácticas e investigaciones nacionales e internacionales; (4) Elaboración de la propuesta metodológica LABTUR en formato de laboratorio urbano experimental de carácter temporal e inmersivo, y elección de las herramientas colaborativas (digitales y analógicas) a utilizar en función del objetivo de cada fase; (5) Convocatoria pública para participar en la Escuela de Verano LABTUR; (6) Desarrollo de las fases de la propuesta metodológica, utilizando la documentación del proceso y sus resultados a través de la plataforma TUR; (7) Conclusiones sobre el potencial de la propuesta, sus lagunas y posibilidades de mejora y desarrollo futuros.

\footnotetext{
${ }^{1}$ Para más información, ver: https://turcocreating.weebly.com/tur19.html
} 
El TUR'19 se preparó con seis meses de anticipación, en coordinación directa con la Ayuntamiento de Cascais, que brindó apoyo logístico y financiero para todo el proceso. El equipo organizador estuvo formado por investigadoras de dos centros de investigación ${ }^{2}$ del ISCTE-IUL, cuyas investigaciones se centran en los temas abordados.

\subsection{Conferencia Internacional: Visión Global}

Aunque el formato de la conferencia internacional institucionaliza un sesgo disciplinar y especialista, permite problematizar los desafíos acumulados sobre una diversidad de experiencias en diferentes contextos. Con el objetivo de proporcionar a los participantes una visión general de las diferentes prácticas y conocimientos, la conferencia se estructuró en cuatro sesiones temáticas: (1) Community Participation and Toolkits; (2) Civic laboratories; (3) Collaboration in digital condition; y (4) Digital Collective Mapping.

\section{Community Participation and Toolkits}

En la primera sesión se presentaron los métodos, conceptos y herramientas a utilizar en los procesos participativos de diseño del espacio urbano en función del propósito, contexto y meta de participación. En esta sesión se concluyó que las herramientas utilizadas, sean analógicas o digitales, deben tener la flexibilidad necesaria para permitir, a través de un enfoque creativo, integrar a diferentes personas a lo largo del proceso de creación, revelando sus necesidades y valorando sus experiencias y conocimientos (Cardoso, et al, 2019).

Una de las experiencias compartidas fue el Laboratorio Abierto de Asunción (ASULAB), impulsado por Ecosistema Urbano, que tuvo como objetivo facilitar la comunicación entre ciudadanos e instituciones y asegurar la implementación del Plan Maestro del Centro Histórico de Asunción, en Perú, de manera abierta, democrática e inclusiva (Ecosistema Urbano, 2014). Este laboratorio, que tuvo como punto clave la participación ciudadana como herramienta de planificación, dejó algunas lecciones importantes para la dinámica de co-creación de LABTUR, tales como: (1) La importancia de experimentar con futuros posibles, a través de acciones urbanas ligeras y rápidas; (2) la importancia de crear una sede que ofrezca rutinas de trabajo diarias, pero también una infraestructura móvil que maximice y acerque el laboratorio a los ciudadanos; (3) el uso de tecnología mixta que permita una mayor inclusión de los involucrados; y (4) conectar a los ciudadanos con su pasado, presente e invitarlos a imaginar el futuro (Ecosistema urbano, 2016).

\section{Civic laboratories}

En la segunda sesión dedicada al tema de los laboratorios cívicos, se compartió la experiencia del Lab Cívico Santiago ${ }^{3}$. El investigador invitado José Carlos Mota trajo la perspectiva de un laboratorio ciudadano liderado por la comunidad creado en Aveiro, Portugal y cuya metodología está inspirada en Experimenta Distrito Madrid ${ }^{4}$ que lleva laboratorios ciudadanos a diferentes barrios de la ciudad. Basado en una cultura de proximidad y partiendo de la ocupación temporal de una asociación local, este laboratorio surgió con el objetivo de prototipar soluciones a los problemas del barrio de Santiago a través de la experimentación ciudadana guiada por mediadores y en la colaboración de diferentes actores (Lab Cívico Santiago, 2019). Este laboratorio utiliza la convocatoria pública como herramienta para promover la ciudadanía. En el cual, los vecinos o grupos locales pueden presentar ideas que serán prototipadas por un corto período de tiempo. Aquí se destacó el papel del prototipo como

\footnotetext{
2 ISTAR-IUL e DINAMIA'CET

3 Para más información, ver: https://labcivicosantiago.wordpress.com/o-que-e-um-laboratorio-civico/

${ }^{4}$ Para más información, ver: http://experimentadistrito.net/
} 
dispositivo de escucha para las comunidades afectadas y su potencial para construir comunidades de práctica que puedan colaborar para responder a un desafío común, pero sin la pretensión de dar respuestas rápidas a problemas agudos (Lab Cívico Santiago, 2019). También se destaca el papel de la mediación, que según Juan Freire (2020, pag.20) "engloba roles diversos que van desde la acción pedagógica para hacer comprensibles los prototipos y proyectos al público en general, a coordinar y gestionar los trabajos que tienen que ver con los cuidados y lo reproductivo, o liderar procesos de investigación y producción. (...) pero a la vez es parte de otras herramientas como los talleres de producción donde cumple funciones específicas”. El prototipo como dispositivo de escucha y el papel de la mediación se explorarán en la metodología LABTUR.

\section{Collaboration in digital condition y Digital Collective Mapping.}

Las dos últimas sesiones estuvieron dedicadas al tema de la participación y colaboración en la era digital y a la reflexión sobre las oportunidades y desafíos del uso de herramientas digitales en procesos que buscan ser más inclusivos y democráticos. La sociedad red ha transformado nuestra vida cotidiana (Castells, 2010). Las herramientas de colaboración innovadoras y las nuevas formas organizativas han contribuido a aumentar las formas de "hacer juntos", mejorando el co-diseño, la co-creación, la coproducción, la cogobernanza y la cooperación (Cardoso et al, 2019). Tomamos como ejemplo el crecimiento de la tecnología de almacenamiento y uso compartido, la democratización de los dispositivos de comunicación móvil y el mapeo basado en plataformas digitales de código abierto que han permitido el acceso a una serie de datos socioespaciales y culturales complejos. Datos georreferenciados y compartidos en tiempo real por usuarios que pueden editar e integrar contenido, pueden enriquecer el espacio físico que se traduce digitalmente con información local (Cardoso, et al, 2019).

Una de las experiencias compartidas por la investigadora Isabel Carvalho involucró el tema del mapeo digital colectivo a través de procesos de participación ciudadana. Las reflexiones sobre el uso de esta herramienta habrán sido muy importantes en las actividades de mapeo que se llevarían a cabo en LABTUR.

Según Ecosistema Urbano (2014), “La visión global [aquí aportada por el intercambio de experiencias] nos proporciona conocimiento, experiencia y un canal de entrada para dinámicas creativas y renovadoras capaces de superar algunas limitaciones del contexto. La dimensión local [con el laboratorio como medio] permite una mirada más cercana, más en contacto con las necesidades directas de la ciudad y sus habitantes y ligada a sus iniciativas e impulsos más genuinos." Así, la reflexión colectiva sobre las experiencias compartidas en diferentes territorios, por expertos nacionales e internacionales, fue fundamental para los participantes de LABTUR, quienes trabajaron durante los próximos diez días en áreas urbanas de origen ilegal (AUGI). Las particularidades de los territorios en estudio, que se presentan a continuación, justifican la temática de esta primera edición, que se centra en las estrategias de intervención del espacio público que promueven la mejora de la calidad de vida de la población.

\section{Estudios de caso: espacio público en áreas urbanas de génesis ilegal}

Los territorios en estudio fueron seleccionados junto con el equipo de la Oficina de Recalificación del Ayuntamiento de Cascais, teniendo como criterio de selección dos Áreas Urbanas de Génesis Ilegal - 
$\mathrm{AUGI}^{5}$ (marcadas en la Figura 1) que estaban en proceso de transición e integradas en una estrategia de recalificación urbana6, en concreto, el Bairro de Cabeço de Mouro (A) y el Bairro dos Peões (B), ubicados en São Domingos de Rana, en el municipio de Cascais, Portugal.

Las AUGl están asociadas a áreas de expansión urbana ilegal y no planificada, ubicadas en las periferias de las grandes áreas metropolitanas del territorio portugués y con origen en las décadas de 1960 y 1970, especialmente en el Área Metropolitana de Lisboa, como consecuencia del éxodo rural. Los flujos migratorios de personas en busca de mejores condiciones laborales en la ciudad y consecuentemente de vivienda, provocaron una gran presión en las áreas urbanas y el repentino crecimiento de barrios clandestinos en vastas áreas dispersas y fragmentadas. Si, por un lado, el precio de la vivienda en los centros urbanos era muy elevado, por otro, la periferia permitió la reproducción de la cultura rural de las familias recién llegadas (Ferreira, 1984), dando lugar a la construcción de viviendas clandestinas en terrenos parcelados sin licencia legal. En estos barrios, la rentabilidad del área privada para la construcción clandestina fue la principal prioridad en detrimento del área destinada al uso público. Según Sílvia Jorge (2010, pag.148), "la población tenía el sueño de construir una casa, no aspiraba a construir la ciudad, lo que condiciona la relación entre lo individual y lo colectivo, entre el espacio privado y el espacio público". La expansión desordenada en un régimen de autoconstrucción y sin planificación institucional, dio lugar a espacios públicos no calificados, que se transformaron en espacios residuales entre edificios.

La Ley No. 91/95 de 2 de septiembre, correspondiente al proceso de reconversión de la AUGI y su inserción legal en la ciudad, trajo esperanza a muchos habitantes involucrados en este fenómeno clandestino. Sin embargo, la lentitud de los procesos de legalización ${ }^{7}$ no atiende las necesidades de los ciudadanos, mostrándose incapaces de "responder tanto a las demandas observadas en la aprobación de planes y en la resolución de la trama burocrática de la legalización territorial, como a las situaciones más críticas, que requieren otros instrumentos legales y urbanísticos "(Raposo et al, 2010, p.120). En cuanto a la calificación de los espacios públicos, a pesar de que esta preocupación comienza a incorporarse al discurso y la práctica de los procesos de reconversión de las AUGl, según Sílvia Jorge, existen algunos impedimentos para la transferencia de tierras al dominio público: “i) falta de tierra libre dentro de los límites del área urbana de génesis ilegal, con todo el espacio adjudicado y [o] construido; ii) falta de capacidad financiera de los propietarios para adquirir tierras para transferir; iii) la falta de interés por parte de los propietarios en la calificación del espacio público (...); iv) cierta desconfianza de los propietarios en relación a los servicios municipales en cuanto al destino de las áreas que serán transferidas, retrasando o haciendo inviable la transferencia; v) (...) propietarios (...) más motivados por la rentabilidad de sus tierras que por las concesiones de equipamiento y / o espacios verdes "(Jorge, 2010, en Fernandes, 2015, p.16-17), resultando en un largo camino de negociaciones entre propietarios y gobierno. Para Borja y Muxi (2003, pags. 70-71), "El espacio público es una conquista democrática. La conquista implica iniciativa, conflicto y riesgo, pero también legitimidad, fuerza acumulada, alianzas y negociación”.

\footnotetext{
5 “AUGI - Áreas Urbanas de Génesis Ilegal, únicamente predios o conjuntos de predios vecinos que, cuando así lo requiera la ley, hayan sido objeto de exploración física de parcelas destinadas a la construcción, de acuerdo al régimen de exenciones previsto en la Ley. № 91/95 del 2 de septiembre." Recuperado de https://www.cascais.pt/ sites/default/files/anexos/gerais/normas augi.pdf

6 En 2008 se creó el Departamento de Recalificación Urbana con el objetivo de rehabilitar, recalificar y reestructurar "los entornos urbanos, [y su integración] en un proyecto estratégico, con otro diseño urbano, corrigiendo asimetrías y unificando el espacio público". Para obtener más información sobre este proceso, visite el sitio web del Ayuntamiento de Cascais: https://www.cascais.pt/sites/default/files/anexos/gerais/4 caracteriza cao urbana.pdf

${ }^{7}$ Hasta la fecha, el proceso de reconversión de ambas las AUGI no se ha completado. El 13.01.2021, el municipio de Cascais decidió sobre el proceso de reconversión urbana de la AUGI en Bairro dos Peões, en São Domingos de Rana. La planta de síntesis se puede consultar en línea: https://geocascais.cascais.pt:8443/pdf/urbanismo/Alvara s 1fase/planta 1fase1502 07.pdf
}

ACE, 16 (46) CC BY-ND 3.0 ES | UPC Barcelona, España | LABTUR: Una contribución metodológica a las prácticas de co-creación del espacio público. DOI: http://dx.doi.org/10.5821/ace.16.46.9893 


\section{ACE Architecture, City and Environment}

E-ISSN 1886-4805

Dado que el espacio público es un indicador de la calidad urbana, algunos estudios como el Project for Public Spaces ${ }^{8}$ (1975) señalan algunos factores importantes que deben ser considerados al momento de evaluar la calidad de los espacios públicos, tales como: (1) accesibilidad y conexiones a un lugar dado; (2) comodidad e imagen, asociada a la percepción de seguridad, limpieza y disponibilidad para sentarse; (3) su diversidad de usos y actividades; (4) y el nivel de sociabilidad (PPS). Sin embargo, es importante evaluar estos factores a la luz de las particularidades y vulnerabilidades del AUGI, considerando sus características morfológicas y tipológicas, pero también las experiencias, aspiraciones, valores y prácticas socioculturales de las personas que construyeron sus barrios con sus propias manos. Además, es importante considerar la duración de los procesos de legalización que impactan los procesos de recalificación de AUGI.

Ante la realidad del crecimiento urbano insostenible en las periferias y el hecho de que el espacio público - bien colectivo y estructurador de la forma de vida y el bienestar de las comunidades - es uno de los factores más afectados por este fenómeno clandestino, impactando la calidad de vida en el AUGI, el tema del espacio público se convirtió en una prioridad para LABTUR.

Figura 1. Imagen de satélite donde se marcan en amarillo las AUGI del municipio de Cascais y en rojo los territorios en estudio

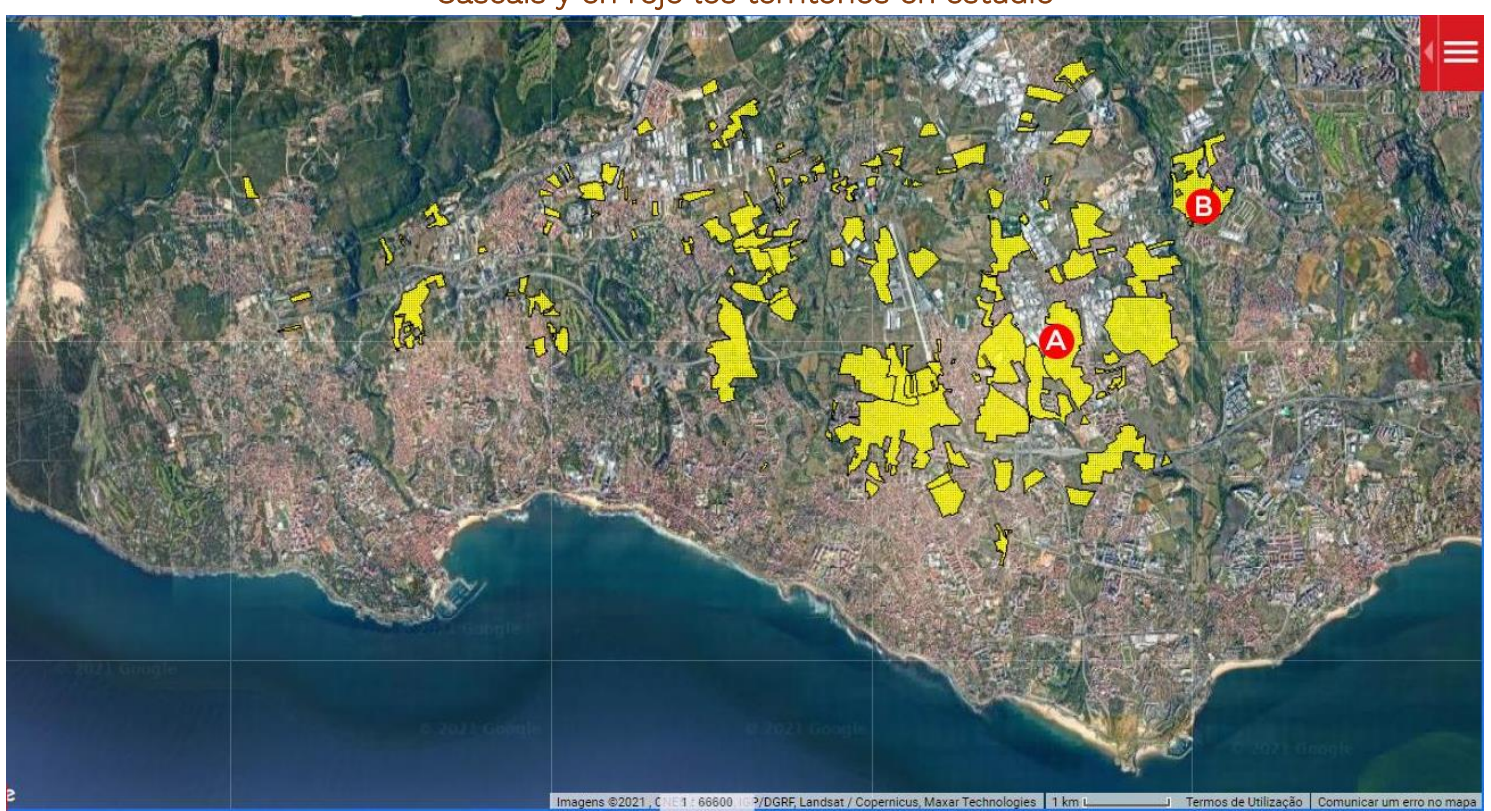

Fuente: Geo Cascais.

\section{Laboratorio urbano experimental LABTUR: metodología y herramientas colaborativas}

El laboratorio urbano experimental LABTUR buscó crear un entorno de reflexión entre la investigación y la práctica, proporcionando un período inmersivo de intercambio de conocimientos y experimentación colaborativa entre la academia, el sector público y la ciudadanía, en un contexto situado. La exploración de nuevas formas de resolver el problema presentado requiere diálogo entre diferentes actores, mediación y experimentación. Es en base a estos tres factores que se desarrolló

\footnotetext{
8 Para más información, ver: https://www.pps.org/
} 
la metodología, en una lógica colaborativa y valorando el AUGI, para sus habitantes, y buscando identificar el rol de cada actor en estos procesos. La metodología consta de cinco fases: (1) aproximación, (2) reconocimiento, (3) ideación, (4) prototipado y (5) presentación. Todas serán sistematizadas y desarrolladas a continuación (Figura 2). Además, la metodología combina técnicas de investigación convencional con técnicas investigación participativa (LNEC, 2013). El conjunto de herramientas colaborativas adoptado se probó en la práctica con el objetivo de promover un lenguaje compartido entre los diferentes actores, en función de los objetivos de cada fase y sus dinámicas de co-creación. Su elección se basó en las experiencias ya realizadas en cada investigación en curso. Teniendo en cuenta el problema anterior, se propuso reflexionar sobre procesos de co-creación del espacio público que pudieran experimentarse en los territorios en el corto plazo e impactar decisiones en el largo plazo.

Figura 2. Metodología TUR

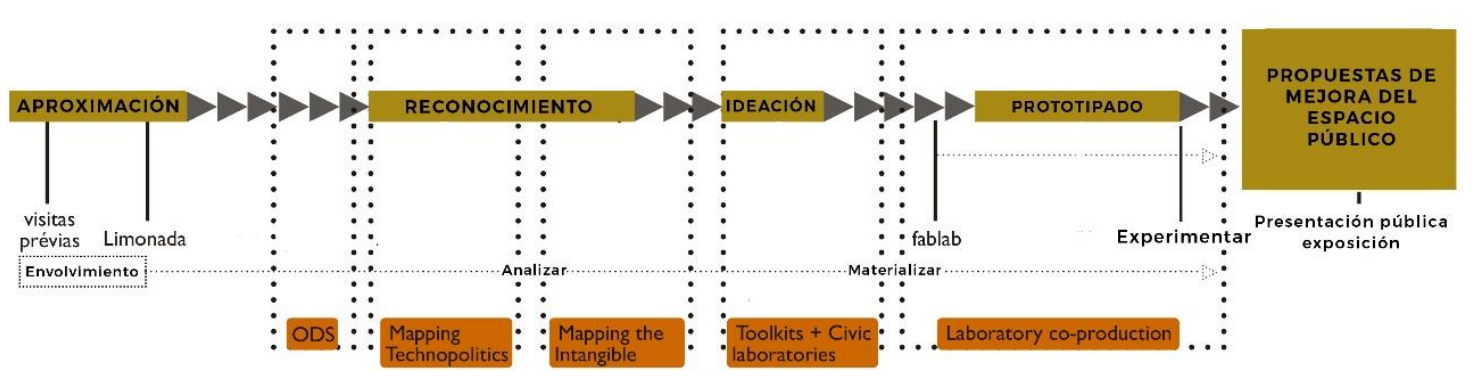

Fuente: TUR

\section{Fase I. Aproximación: Identificación del problema}

Para una mejor comprensión de la realidad socioespacial de los casos de estudio y para poner como punto de partida a los residentes y sus inquietudes (Sanoff, 2000), fue necesario adoptar un enfoque que permitiera la creación de un vínculo con la comunidad. Así, la primera fase de la metodología se inició tres meses antes del inicio de TUR'19. El apoyo del Ayuntamiento de Cascais fue extremadamente importante tanto en la recopilación de información sobre los barrios como en el contacto con las respectivas Administraciones Conjuntas de residentes / propietarios. Mediante la combinación de métodos cuantitativos y cualitativos, se utilizó primero el análisis documental y cartográfico como técnicas de recolección de información, junto con las visitas de campo a los barrios. Se realizaron acciones de escucha en el territorio con el objetivo de conocer a los vecinos de la AUGI y mapear colectivamente las principales problemáticas vividas a nivel del espacio público (Figuras 4 y 5).

Figuras. 3, 4 y 5. Acción 1: Limonada en acción - El diagnóstico participado

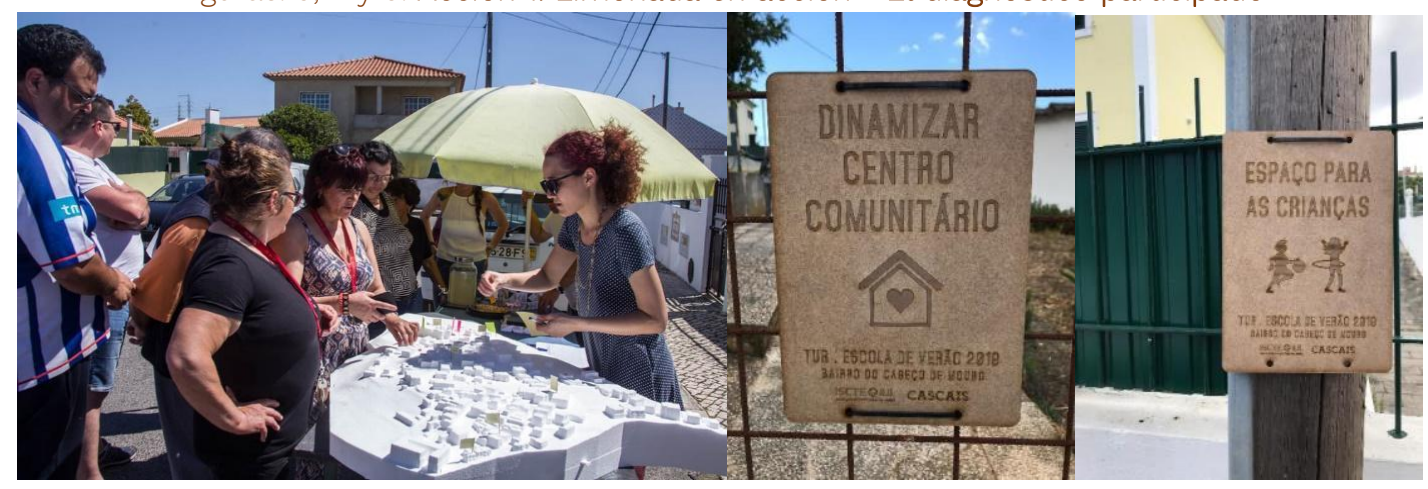

Fuente: Autoría propia.

ACE, 16 (46) CC BY-ND 3.0 ES | UPC Barcelona, España | LABTUR: Una contribución metodológica a las prácticas 9 de co-creación del espacio público. DOI: http://dx.doi.org/10.5821/ace.16.46.9893 
Las dinámicas se basaron en un modelo del barrio a escala 1: 400 (figura 3), herramienta muy utilizada en técnicas de investigación-acción participativa para involucrar a las personas en el proceso. Junto con el modelo, se ofreció una limonada a los ciudadanos con el fin de desbloquear diálogos, brindando así información cualitativa sobre las experiencias en los barrios.

Los resultados fueron presentados en formato expositivo en la biblioteca municipal de São Domingos de Rana con el objetivo de despertar el interés de la población por LABTUR. Esta técnica de sensibilización tiene como objetivo informar a la comunidad sobre el problema (LNEC, 2013).

A pesar de las similitudes en cuanto a carencias a nivel de espacio público, podemos destacar algunas características que diferencian a los barrios en su morfología, localización y dimensión, que son importantes para el transcurso del laboratorio:

\section{Bairro dos Peões}

Se encuentra en el límite del municipio de Cascais y fue construido en la cima de una colina. Como podemos ver en las imágenes 6 y 7 , el barrio cuenta con un tejido urbano orgánico que se desarrolló en base a las necesidades de sus residentes, donde los vacíos representan predominantemente la calle que da acceso a las viviendas. La mayoría de las calles no tienen aceras y el movimiento de peatones se comparte con la carretera (figura 10). Además de la tipología de calle, no existen espacios públicos con potencial de permanencia y encuentro -como plazas, parques o jardines- limitándose a la existencia de espacios colectivos como asociaciones locales y cafés. Sin embargo, la colina presenta un potencial de recalificación?

En cuanto a la accesibilidad y conexiones, hay falta de transporte público y dependencia del transporte individual. En las acciones realizadas con la población, los principales problemas identificados fueron: (1) la falta de espacios para que los niños jueguen; (2) la falta de espacios para la interacción social al aire libre, (3) la falta de mobiliario urbano, (4) el uso excesivo de automóviles y la falta de estacionamiento reduce la calidad de los peatones, y (5) la ocupación excesiva de automóviles en Largo dos Peões por parte de no -residentes que viajan al barrio para almorzar en el restaurante (Figura 9).

El Bairro de Cabeço de Mouro (Figura 11 y 12), actualmente más integrado en el tejido urbano de la ciudad, disfruta de mejores conexiones y acceso al transporte público. Las calles de este barrio (Figura 13 y 14) son más anchas, con suficientes aceras para caminar y estacionar autos. Sin embargo, de manera similar a Bairro dos Peões, hay una ausencia de espacios de permanencia y reunión a nivel del espacio público, aunque el barrio tiene muchos lotes vacíos (Figura 15) que podrían negociarse para su transferencia al dominio público.

En cuanto a espacios e instalaciones colectivas, además de un café, hay una escuela, un centro comunitario y un campo de fútbol. En las acciones realizadas con la población, los principales problemas identificados fueron: (1) la falta de espacios para que los niños jueguen; (2) falta de espacios al aire libre adaptados a las personas mayores, (3) remodelación del arroyo, (4) dinamización del centro comunitario y (5) mejora del campo de fútbol.

\footnotetext{
${ }^{9}$ El 21 de enero de 2021 fue deliberado el proceso de reconversión de AUGI Bairro dos Peões. De acuerdo con el plan de síntesis propuesto, parte de esta área verde fue transferida al dominio público municipal. Esta área fue considerada como un espacio verde en la propuesta actual para la reconversión del Bairro dos Peões, debido a la imposibilidad de construcción en la zona. Recuperado de https://geocascais.cascais.pt:8443/pdf/urbanismo LAlvaras 1fase/planta 1fase1502 07.pdf
}

ACE, 16 (46) CC BY-ND 3.0 ES | UPC Barcelona, España | LABTUR: Una contribución metodológica a las prácticas de co-creación del espacio público. DOI: http://dx.doi.org/10.5821/ace.16.46.9893 


\section{ACE Architecture, City and Environment}

Figuras 6, 7, 8, 9 y 10. Imágenes de satélite del Bairro dos Peões y perspectivas de la calle, São Domingos de Rana, Cascais, Portugal
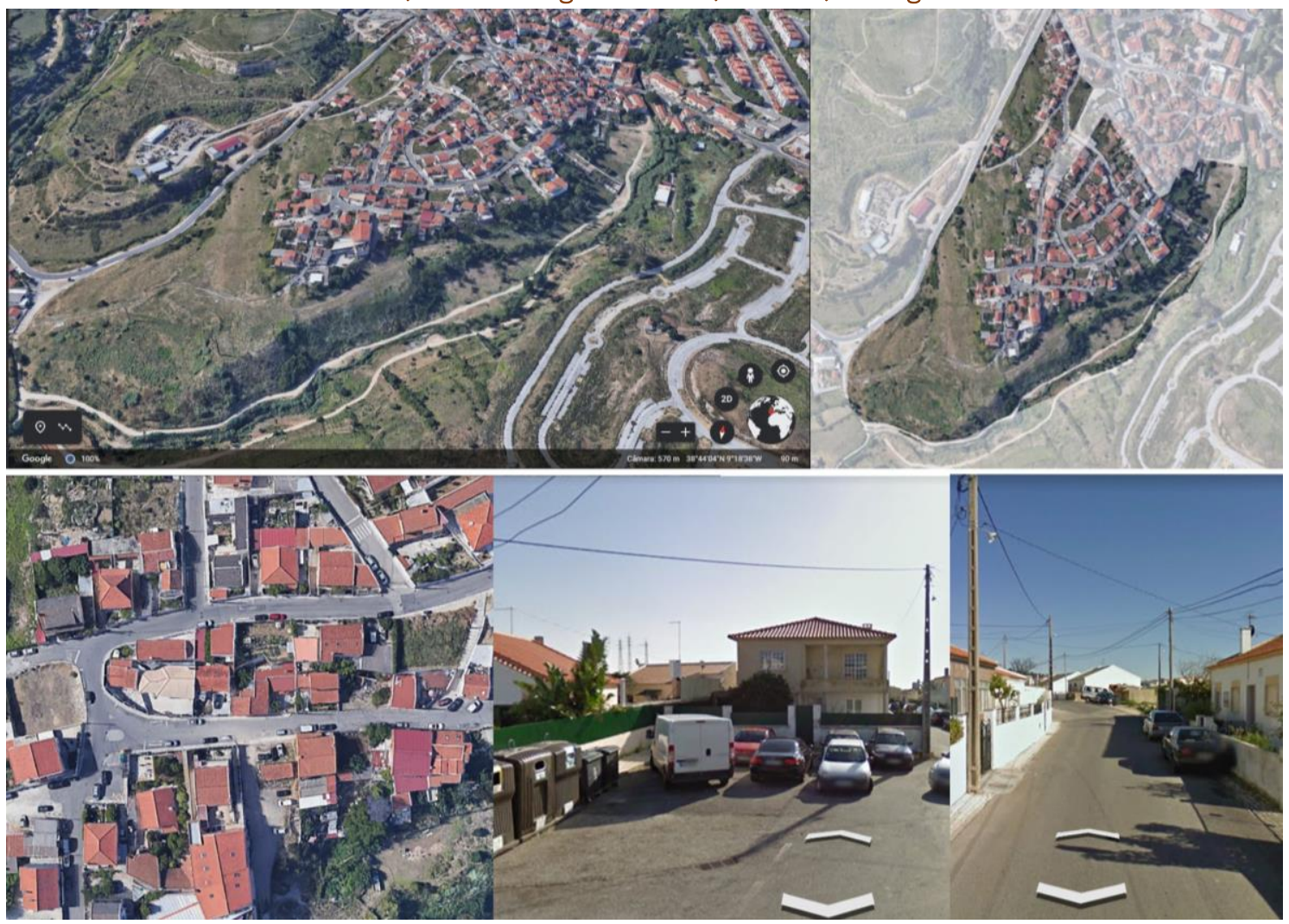

Fuente: Google Earth.

\section{Bairro de Cabeço de Mouro}

En ambos barrios también podemos observar que las casas son en su mayoría viviendas unifamiliares con espacio libre dentro de su lote (patio trasero). Como el espacio público es prácticamente inexistente, la gente utiliza poco espacio exterior.

\section{Fase // Reconocimiento: Mapeo e identificación}

La fase de reconocimiento del territorio da inicio a la Escuela de Verano. A partir de los datos ya recolectados sobre los territorios y la identificación inicial de problemas sentidos por la población local, los 20 participantes de LABTUR conformaron grupos de trabajo interdisciplinarios compuestos por estudiantes de arquitectura, investigadores y técnicos de CMC que se reunieron durante dos semanas en la biblioteca municipal. Es importante mencionar que, debido a las barreras logísticas, no fue posible integrar a los vecinos de los barrios en los grupos de trabajo inicialmente previstos. Así, fue necesario utilizar herramientas que funcionaran como dispositivos de escucha y promovieran su colaboración in situ a través de las actividades diarias en el territorio.

En la primera semana, a través de un enfoque teórico-práctico, LABTUR reunió masterclasses temáticas - donde se presentaron conceptos, metodologías y herramientas - con desafíos prácticos en el campo. Las primeras masterclasses (1) “AUGl: gestión del territorio en Cascais" y (2) "Sostenibilidad: SGD y economía circular", presentaron la visión del municipio de la AUGl y la visión

ACE, 16 (46) CC BY-ND 3.0 ES | UPC Barcelona, España | LABTUR: Una contribución metodológica a las prácticas de co-creación del espacio público. DOI: http://dx.doi.org/10.5821/ace.16.46.9893 


\section{ACE Architecture, City and Environment}

académica de los desafíos para su desarrollo más sostenible. Por la tarde se organizaron caminatas guiadas con vecinos de los barrios (Figuras 16 y 17), técnica que contribuyó al reconocimiento del territorio desde la perspectiva de quienes lo habitan y quienes lo construyeron con sus propias manos. De esta forma, fue posible confrontar las perspectivas de los diferentes actores involucrados.

Figuras 11, 12, 13, 14 y 15. Imágenes de satélite del Bairro do Cabeço de Mouro y perspectivas de la calle, São Domingos de Rana, Cascais, Portugal

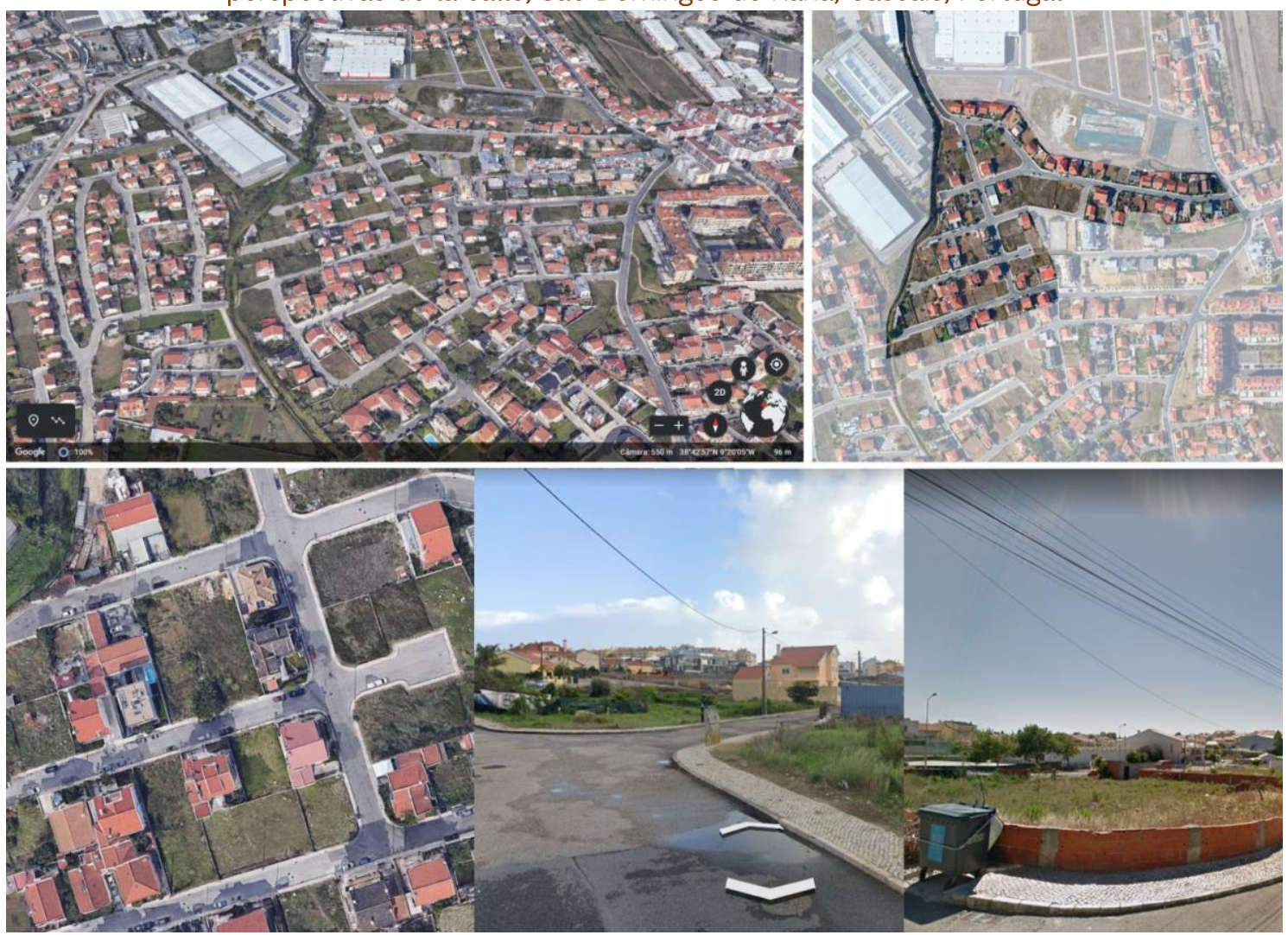

Fuente: Google Earth.

Figuras 16 y 17. Entrevistas y visitas guiadas con residentes de los barrios.

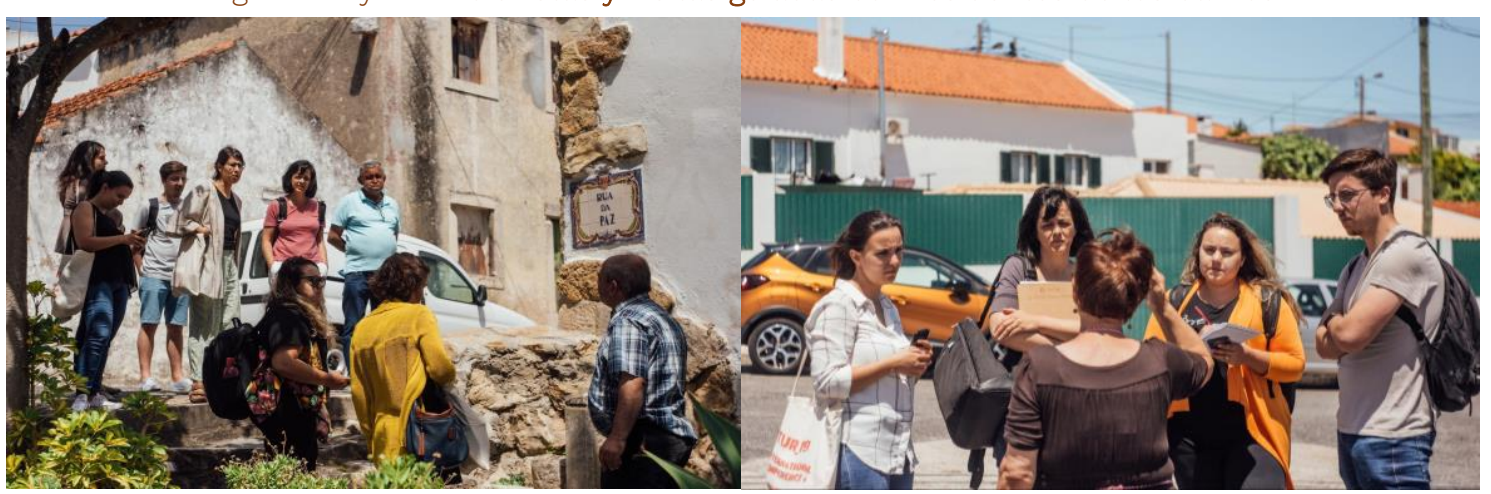

Fuerte: Autoría propia.

Considerando las particularidades de las AUGI y la problemática del espacio público, constituido aquí como un espacio residual entre edificios. Intervenir para su calificación requiere, sobre todo, comprender cómo se desarrolla la vida pública (Gehl, et al, 2013), considerando las dinámicas sociales 
existentes, los espacios de los que se apropian los vecinos (Raposo et al, 2010, p.155-156), los espacios afectivos, las oportunidades existentes y las barreras de intervención. Con este fin, se presentaron en las masterclasses "Tecnopolítica y prácticas urbanas" (3) y "Mapeo del patrimonio inmaterial" (4) algunas técnicas y herramientas que ayudarían en este estudio.

Combinando técnicas como la observación directa ${ }^{10}$ y recorridos guiados y exploratorios, se utilizó la técnica de mapeo colectivo. "Todo mapa es una representación ideológica y, a través de un mapeo, se construyen visiones críticas de lo que nos rodea”. (Lafuente et al, 2017, p.4). De manera similar a la investigación presentada por Isabel Carvalho en la conferencia, utilizando dispositivos móviles, fue posible agregar colectivamente, en tiempo real e in situ, datos georreferenciados que podrían actualizarse diariamente y luego compartirse más ampliamente. En los smartphones de los participantes se instaló la aplicación "myTrack" (Figura 18 y 19), mediante la cual los participantes pudieron registrar los recorridos realizados por el barrio, cruzando datos cuantitativos (número de espacios expectantes o servicios existentes, por ejemplo) y cualitativos (fotos, videos, notas personales o comentarios de los residentes).

Aunque el mapeo fue elaborado en la práctica por los participantes, los diálogos con la población local permitieron "transcender la mera información física, para encontrarnos mapas de gentes, de vecinos y vecinas, de afectos e saberes" contribuyendo a la producción de "otras formas de conocimiento, otras formas de acceso al mismo y, en definitiva, desafiar los relatos dominantes" (Lafuente et al, 2017, pag.4). Las actividades de mapeo ayudaron en la construcción colectiva de una línea de tiempo (Figura 20) de los barrios. En él se combinó la información recolectada sobre la formación de las AUGI, a las narrativas individuales y colectivas de los vecinos, sus historias de llegada a los barrios y hechos colectivos.

Figura 18 y 19. Actividades de mapeo digital - Aplicación Minha Rota
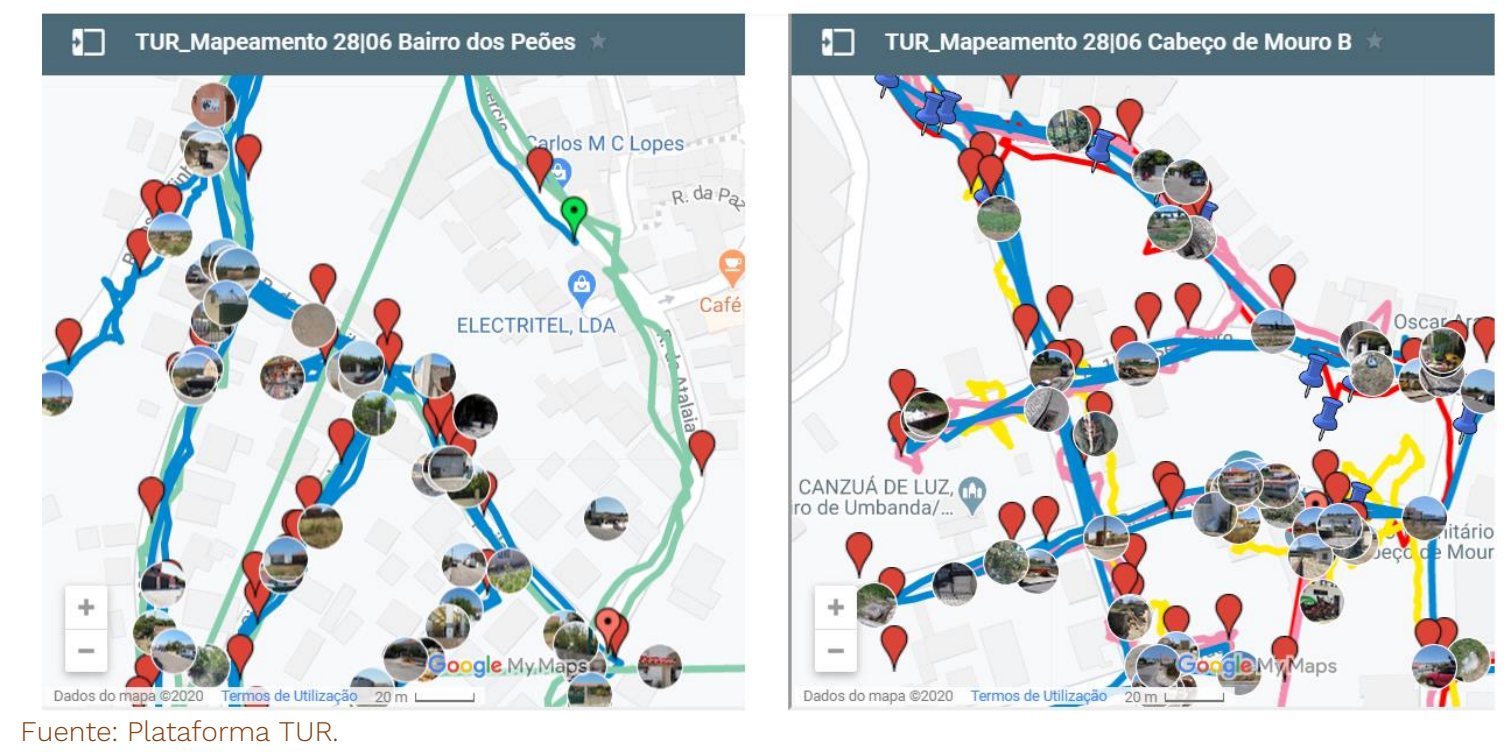

Al final de la jornada, los mapeos de cada grupo se compartieron entre todos a través de la plataforma TUR $^{11}$ y se trasladaron colectivamente a un modelo físico (Figuras 21, 22 y 23) de los barrios, que sirvió de base para la discusión y expresión de múltiples realidades socioespaciales, permitiendo comparar

\footnotetext{
10 Según Gehl (2013), una de las herramientas más utilizadas en los estudios de la vida pública

${ }^{11}$ Para más información, ver: https://turcocreating.weebly.com/plataforma.html
} 
y sistematizar parámetros, uniendo las dimensiones tangibles e intangibles de los barrios bajo las diferentes lecturas y visiones críticas de diferentes actores.

El modelo también funcionó durante todo el proceso como un dispositivo de comunicación diaria con la comunidad, ubicado en la biblioteca municipal, un espacio abierto al público.

Esta fase nos permitió observar que los barrios tienen diferentes dinámicas socio-territoriales. Las relaciones de barrio son más visibles en Bairro dos Peões, donde la población usa más la calle y muestra un mayor sentido de pertenencia al barrio y de valoración de su historia. Esta característica también determinó el tipo de participación de la población en las actividades realizadas en el campo.

Figura 20. Cronología construida en LABTUR por los participantes. Información sobre los barrios de Cabeço de Mouro y Peões. Herramienta: Timeline JS

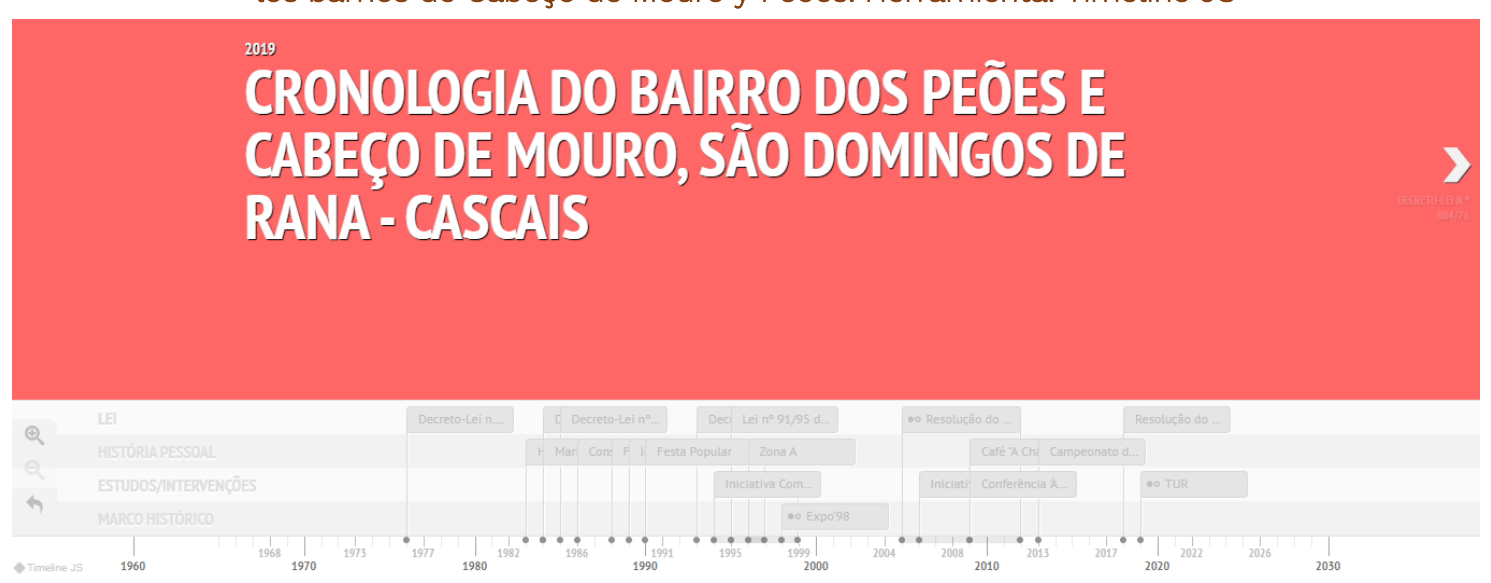

Fuente: Plataforma TUR.

Figura 21, 22 y 23. Actividades de mapeo analógico - modelo físico

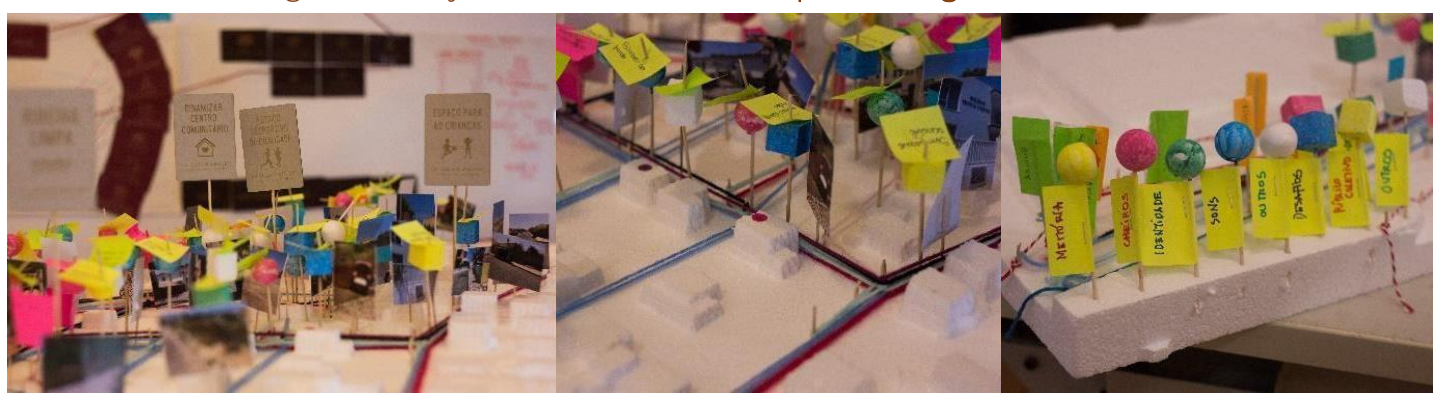

Fotos: Autoría propia.

Fase III Ideación: propuestas de codiseño

La propuesta para la fase de ideación se basa en la necesidad de diálogo y colaboración multiactor para el desarrollo del proceso de co-diseño. Sin embargo, la ausencia de ciudadanos en los grupos de trabajo requirió la activación de dinámicas de co-creación in situ. Según Zamenopoulos y Alexiou (2018, pag.24) “las personas tienen conocimientos valiosos relacionados con su propia situación y circunstancias, que los expertos externos no tienen y que solo pueden descubrirse cuando las personas participan activamente en el diseño. Al mismo tiempo, este tipo de conocimiento es fundamental para la generación de nuevas ideas".

ACE, 16 (46) CC BY-ND 3.0 ES | UPC Barcelona, España | LABTUR: Una contribución metodológica a las prácticas de co-creación del espacio público. DOI: http://dx.doi.org/10.5821/ace.16.46.9893 
Como se mencionó anteriormente, el proceso de reconversión de AUGl normalmente implica la legalización de los lotes, dejando a un segundo plano la valorización del espacio público. Dar a conocer este tema requiere la implicación de la ciudadanía en el ejercicio de futuros alternativos para los espacios comunes de sus barrios.

La fase anterior permitió a los ciudadanos conectarse con su pasado y ayudó a captar la percepción de su situación actual. En esta etapa, se invitó a los ciudadanos a imaginar el futuro, los recursos que se necesitarían para hacerlo realidad y los actores que podrían estar involucrados. La red de actores locales se identificó durante el proceso con la colaboración de todos. Para el análisis de datos en una red, se utilizó kumu.io, una plataforma interactiva y colaborativa de código abierto (Figura 24).

Figura 24. Red de actores construida en LABTUR por los participantes. Información sobre los barrios de Cabeço de Mouro y Peões

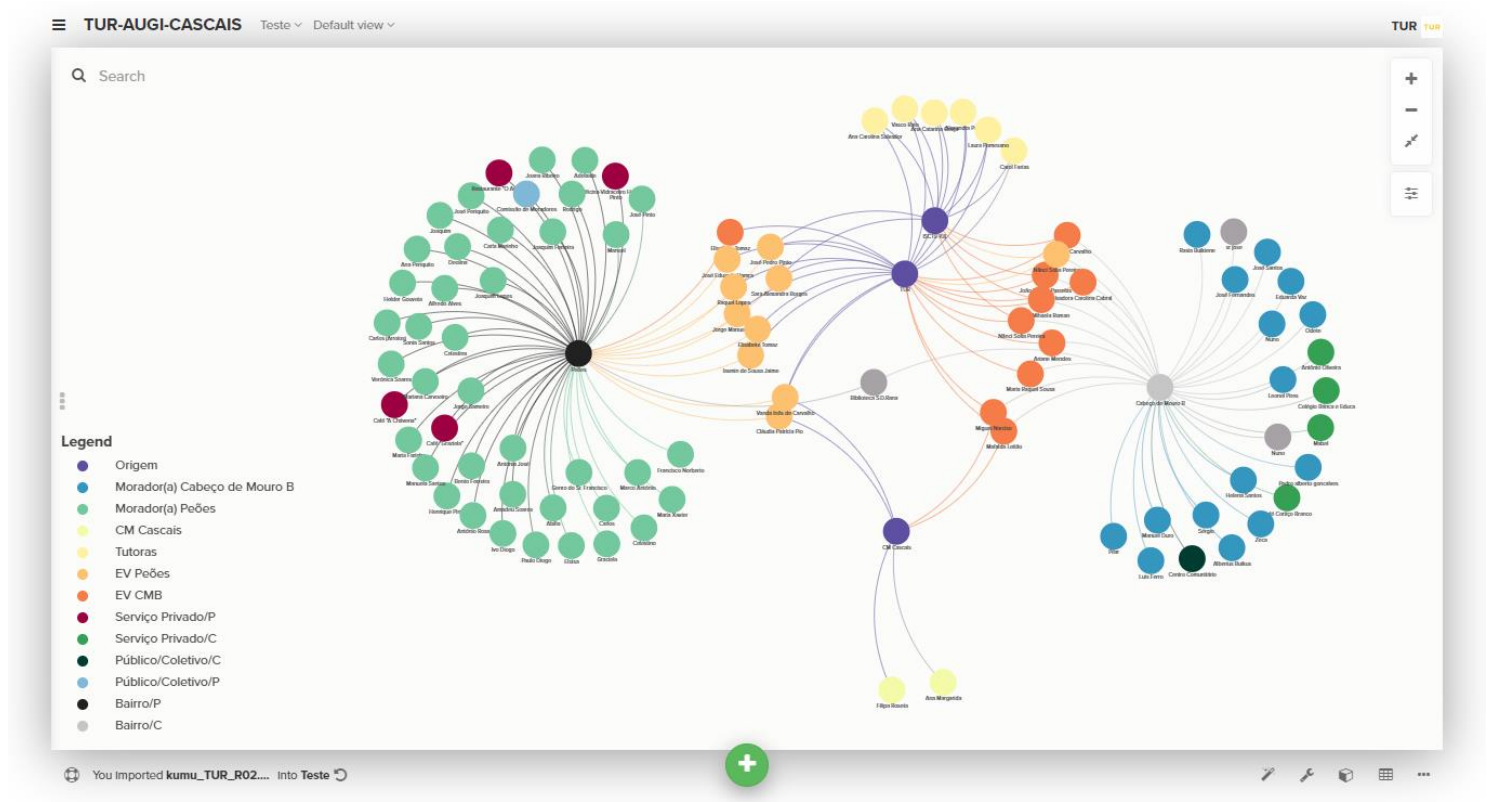

Fuente: Plataforma TUR.

La quinta y última masterclass "Laboratorios cívicos y herramientas de participación", introdujo una herramienta basada en la lógica de la valoración y preferencia visual (LNEC, 2013) y que fue diseñada con el objetivo de involucrar a la población local en el proceso de codiseño. Una herramienta portátil que se puede aplicar rápidamente y en cualquier contexto.

La propuesta era vincular un problema a una posible solución a través de un sistema de votación, promoviendo un diálogo sobre las opciones tomadas. Así, se construyó un kit con tarjetas de problemas (mapeadas en la fase I) y fotografías de espacios públicos. Se pidió a los residentes que eligieran un problema y clasificaran numéricamente las posibles soluciones para un contexto específico (Figuras 25 y 26), identificando también los recursos necesarios y los actores que podrían estar involucrados.

Otras posibilidades se anotaron en post-its y se analizaron más tarde. Fue interesante ver en esta actividad que los proyectos más votados fueron proyectos en los que las personas pudieron identificar posibilidades de realización inmediata, como pinturas en el piso y muebles que eran fáciles de construir y montar, pero que ofrecían resistencia y longevidad.

ACE, 16 (46) CC BY-ND 3.0 ES | UPC Barcelona, España | LABTUR: Una contribución metodológica a las prácticas de co-creación del espacio público. DOI: http://dx.doi.org/10.5821/ace.16.46.9893 


\section{ACE Architecture, City and Environment}

E-ISSN $1886-4805$

Estas opciones pueden estar directamente vinculadas a las características de los propios barrios autoconstruidos. Esta herramienta demostró ser muy eficaz en la creación de un lenguaje compartido, proporcionando un diálogo con los ciudadanos sobre las soluciones que les gustaría ver en sus barrios. Sin embargo, un banco de imágenes predeterminado puede inducir respuestas y limitar la creatividad colectiva.

Figuras 25 y 26. Actividades de co-creación con la población local utilizando herramientas desarrolladas para esta fase. Barrios de Peões y Cabelo de Mouro. Desarrollo de propuestas basadas en los problemas mapeados

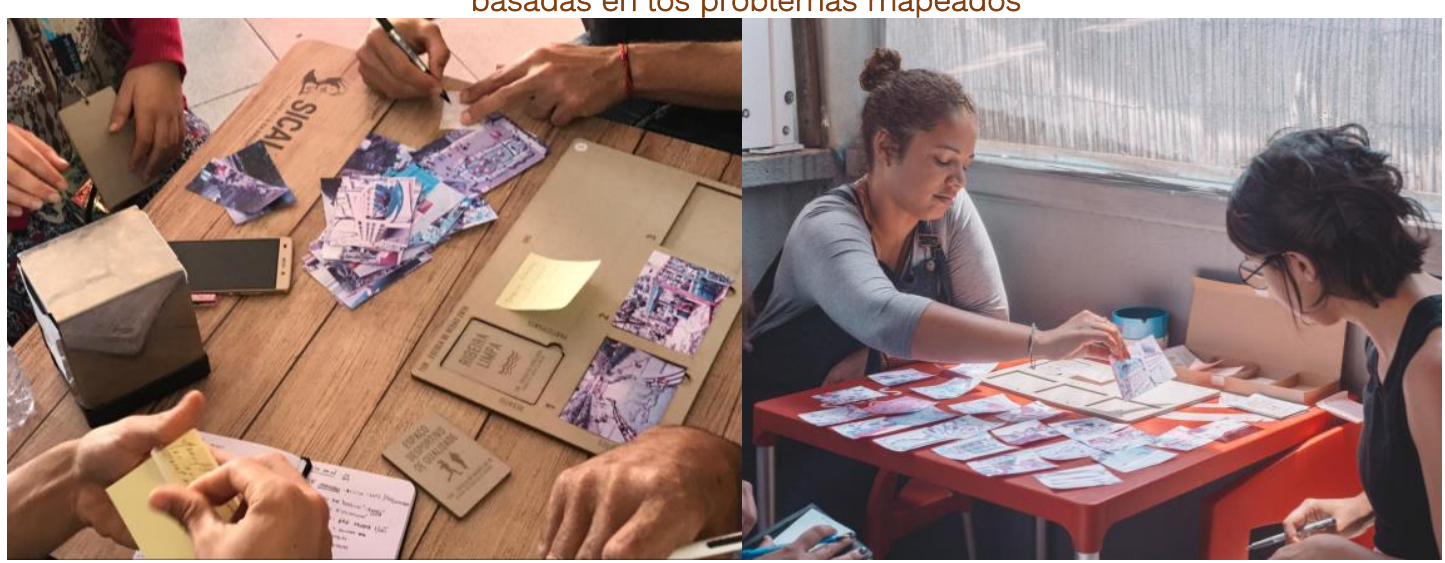

Fotos: Autoría propia.

En todas las masterclasses, los participantes recibieron un juego de tarjetas (tarjetas de conceptos y tarjetas de herramientas) en torno a los temas tratados, ayudando a los grupos en el día a día en los desafíos lanzados (Figuras 27 y 28).

Esta herramienta tuvo como objetivo promover un lenguaje compartido (Sanders et al, 2008) entre los diferentes actores, ayudando a organizar, categorizar y priorizar ideas al final de cada día, cuando los grupos se reunían para compartir sus reflexiones y resultados diarios (Figuras 29, 30 y 31) siguiendo un ejercicio reflexivo.

Figuras 27 y 28. Tarjetas con conceptos y herramientas sobre los temas de las masterclasses. Esta herramienta está disponible en la plataforma TUR bajo una licencia abierta Creative Commons

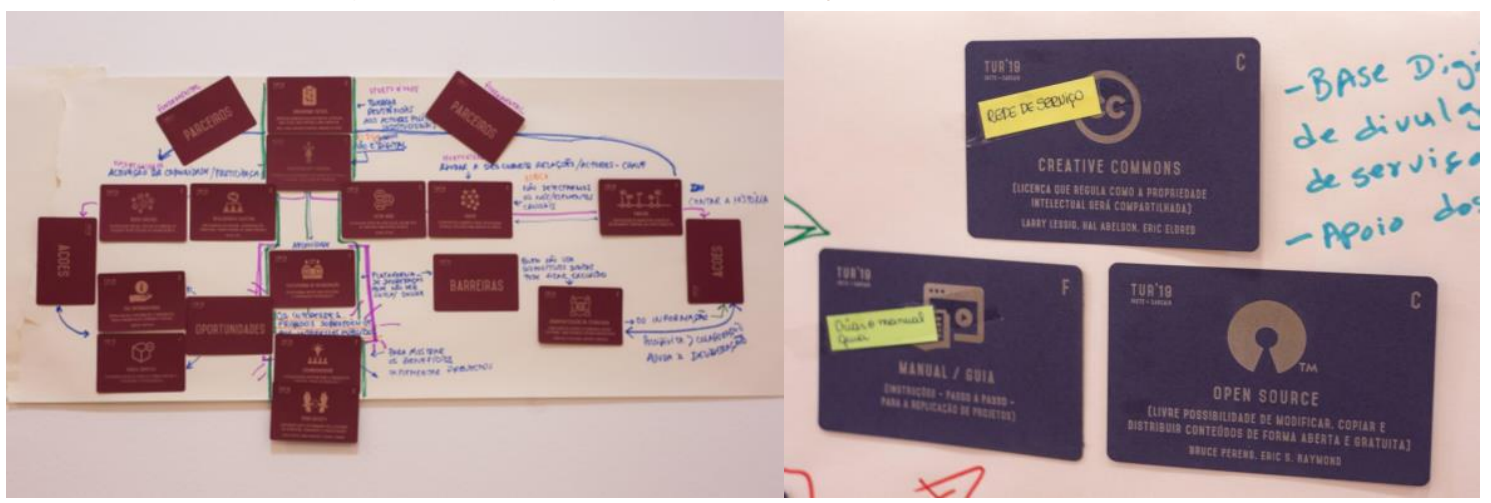

Fotos: Elaboración propia.

ACE, 16 (46) CC BY-ND 3.0 ES | UPC Barcelona, España | LABTUR: Una contribución metodológica a las prácticas de co-creación del espacio público. DOI: http://dx.doi.org/10.5821/ace.16.46.9893 


\section{ACE Architecture, City and Environment}

E-ISSN 1886-4805

Figuras 29, 30 y 31. Actividades de co-creación entre estudiantes, investigadores y técnicos de CMC en la Biblioteca São Domingos de Rana, Cascais. Desarrollo de propuestas basadas en los problemas mapeados

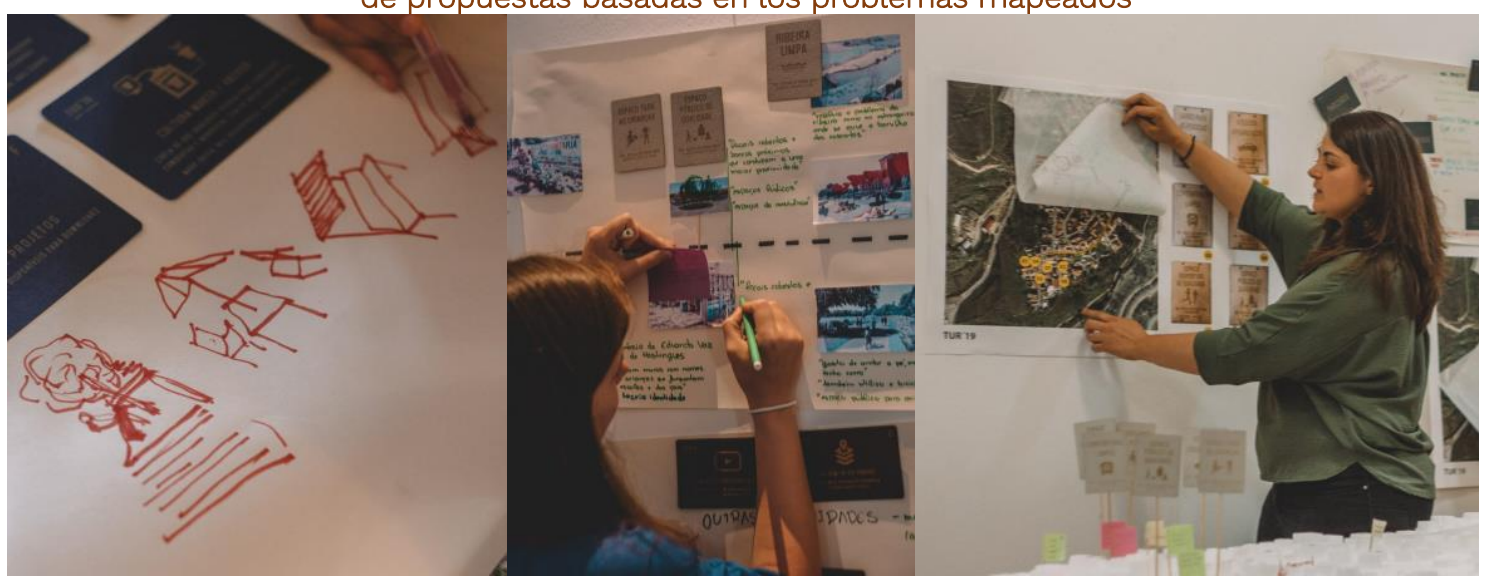

Fotos: Autoría propia.

\section{Fase IV. Prototipado: Acciones de activación del espacio público}

Esta fase tuvo lugar en Vitruvius FabLab, un laboratorio de fabricación digital asociado a uno de los centros de investigación de la universidad. Como parte de una red global, los FabLabs son laboratorios de prototipado (Gershenfeld, 2005) que surgen dentro de una lógica de producción colaborativa experimental, a través del acceso a tecnologías de fabricación digital (como fresadora CNC, impresora 3D y corte por láser). La cultura del prototipado, "heredera de las prácticas experimentales del laboratorio" permite "evocar nuestra capacidad de anticipar, modelar o prefigurar soluciones todavía incompletas, tentativas o provisionales a los problemas” (Lafuente, 2005, pag.2).

Siguiendo la lógica de la ciudad como laboratorio y escenario de experimentación, presentada en este artículo, en lugar de propuestas cerradas, los participantes crearon objetos y toolkits (Figuras 32, 33 y 34) que tenían como objetivo experimentar futuros alternativos, dar visibilidad a las potencialidades existentes en territorios y activar redes locales mapeadas.

Inspirado en experiencias de intervenciones tácticas globales impulsadas por laboratorios como "Ocupa tu calle12" o "Instituto A Cidade Precisa de Você13", uno de los grupos propuso ocupar un área comúnmente utilizada para estacionamiento de automóviles en Bairro do Peões (Figura 9). Este estacionamiento fue un problema identificado por los vecinos y asociado en la fase de ideación a un posible espacio para que los niños jueguen. A través de acciones ligeras, rápidas y de bajo costo, el espacio urbano fue apropiado para uso común, permitiendo probar temporalmente nuevos usos. Antes de que los autos llegaran al sitio, rodeamos el espacio con plantones de árboles provistos por el Ayuntamiento y en poco tiempo, la calle fue ocupada por niños que se apropiaron de los kits de herramientas construidos por los participantes y comenzaron a pintar juegos en el piso (Figura 33 y 34).

Aunque temporalmente, los residentes tuvieron la oportunidad de experimentar uno de los posibles futuros que imaginaban. Algunos vecinos se detuvieron en la calle para jugar (Figura 35), otros dejaron sus sugerencias e ideas para un espacio permanente (Figura 37).

\footnotetext{
12 Para más información, ver: https://ocupatucalle.com/

${ }^{13}$ Para más información, ver: $\underline{\text { https://www.acidadeprecisa.org/ }}$
} 


\section{ACE Architecture, City and Environment}

E-ISSN 1886-4805

En Cabeço de Mouro, donde se observó que las calles estaban desiertas la mayor parte del día, los niños del barrio volvieron a ser la clave para activar el espacio público mediante juegos intergeneracionales disponibles en un recorrido previamente trazado (Figuras 39, 40 y 41). Según Pagano (2013, pag.354) "Las intervenciones urbanas Do-it-yourself crean un espacio necesario para la conexión y el diálogo dentro de las comunidades”. Así, el prototipo se convierte en un dispositivo de escucha sobre futuros alternativos.

De manera similar a la mediación realizada en Lab. Cívico Santiago, la mediación de LABTUR fue concebida por las investigadoras que concibieron el proyecto "como un proceso de investigaciónacción donde el mediador trabaja sobre un problema específico (...) y como parte de su proceso de trabajo cultiva una comunidad de práctica" (Freire, 2020, pág. 19), lo que nos permitió combinar diferentes enfoques, herramientas y métodos de cada investigación en curso, con el conocimiento técnico de Ayuntamiento, el conocimiento académico de otros investigadores y estudiantes y el conocimiento de la ciudadanía.

Figuras 32, 33 y 34. Creación de prototipos de objetos, toolkits y letreros relacionados con cada propuesta de los grupos de trabajo

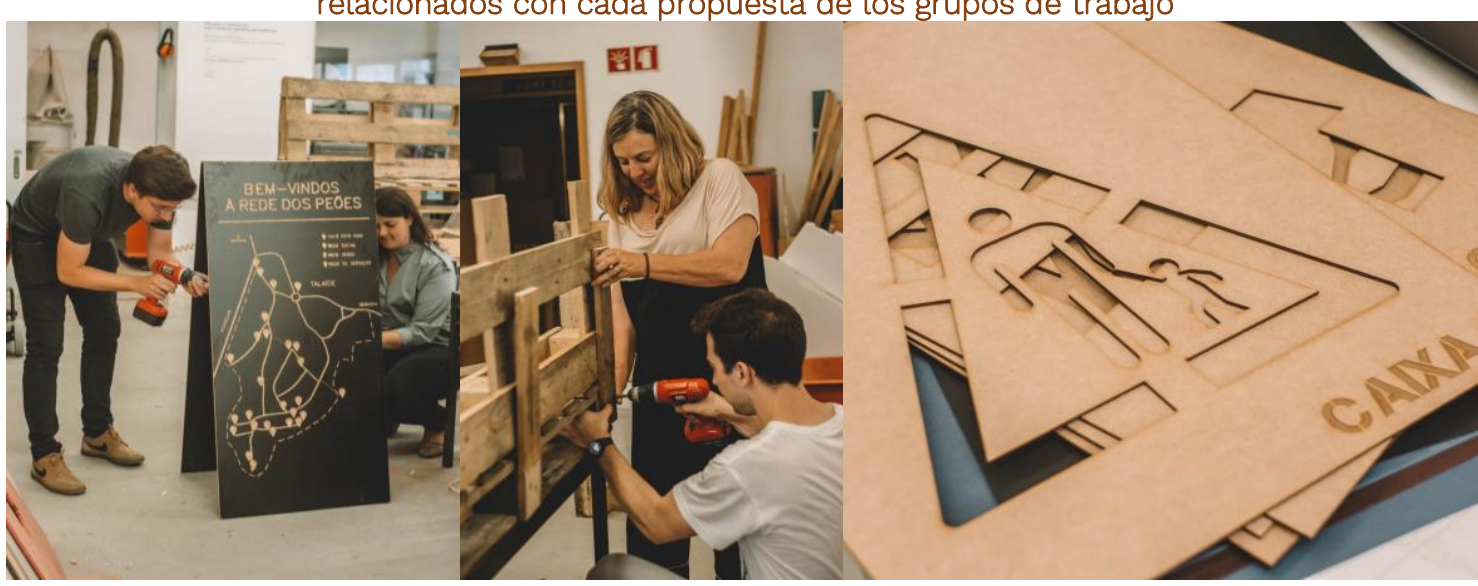

Fotos: Autoría propia.

Figuras 35, 36, 37 y 38. Experimentos en el espacio público con la población de Bairro dos Peões

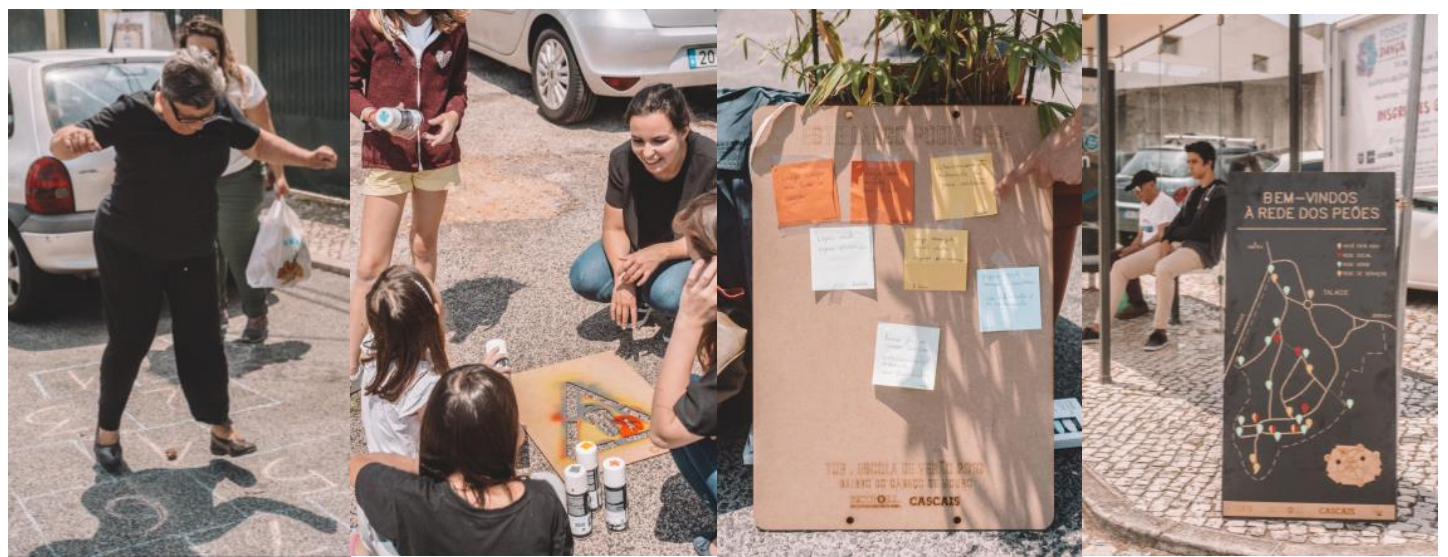

Fotos: Autoría propia.

ACE, 16 (46) CC BY-ND 3.0 ES | UPC Barcelona, España | LABTUR: Una contribución metodológica a las prácticas de co-creación del espacio público. DOI: http://dx.doi.org/10.5821/ace.16.46.9893 


\section{ACE Architecture, City and Environment}

Figuras 39, 40 y 41. Experimentos en el espacio público con los niños de la escuela en el Barrio de Cabeço de Mouro

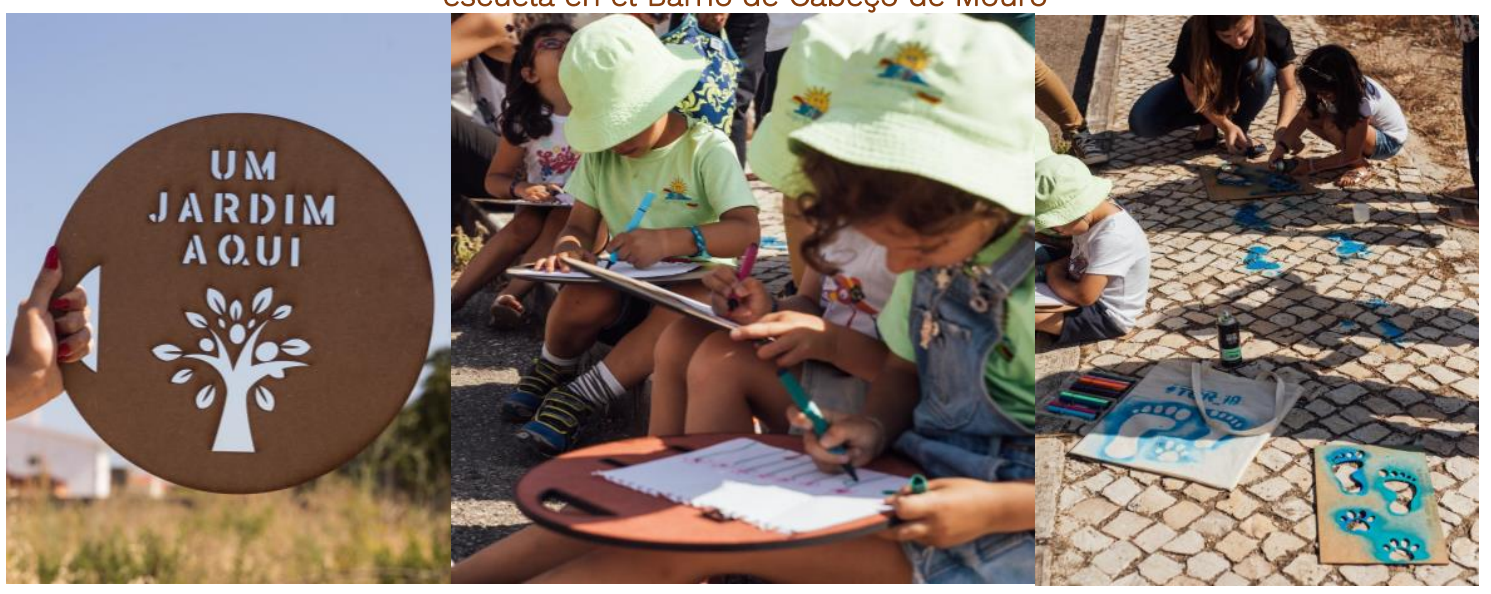

Fotos: Autoría propia.

\section{Fase V Presentación: Devolviendo soluciones a la comunidad}

Al final de LABTUR, las propuestas finales se presentaron a los vecinos del barrio y a todos los involucrados en el proyecto en la Biblioteca de São Domingos de Rana. (Figuras 42, 43 y 44). Dentro de un enfoque experimental, además de las propuestas, se expuso todo el proceso de colaboración, desde el mapeo hasta los procesos de co-diseño y coproducción. La mayoría de los resultados del proceso aún se pueden consultar en la plataforma TUR.

Esta fase permitió un importante momento de reflexión colectiva - involucrando a la academia, municipio y ciudadanía - sobre las dinámicas de co-creación resultantes y sus aportes a procesos más colaborativos en la construcción del espacio público de las AUGI, abriendo nuevos caminos para la solución del problema. Uno de los desarrollos futuros discutidos fue la posibilidad de movilización comunitaria para la revitalización del centro comunitario de Cabeço de Mouro y sus alrededores, en el ámbito del Presupuesto Participativo Municipal.

Figuras 42, 43 y 44. Presentación final de propuestas en la Biblioteca São Domingos de Rana. Los paneles finales se pueden consultar en la plataforma TUR

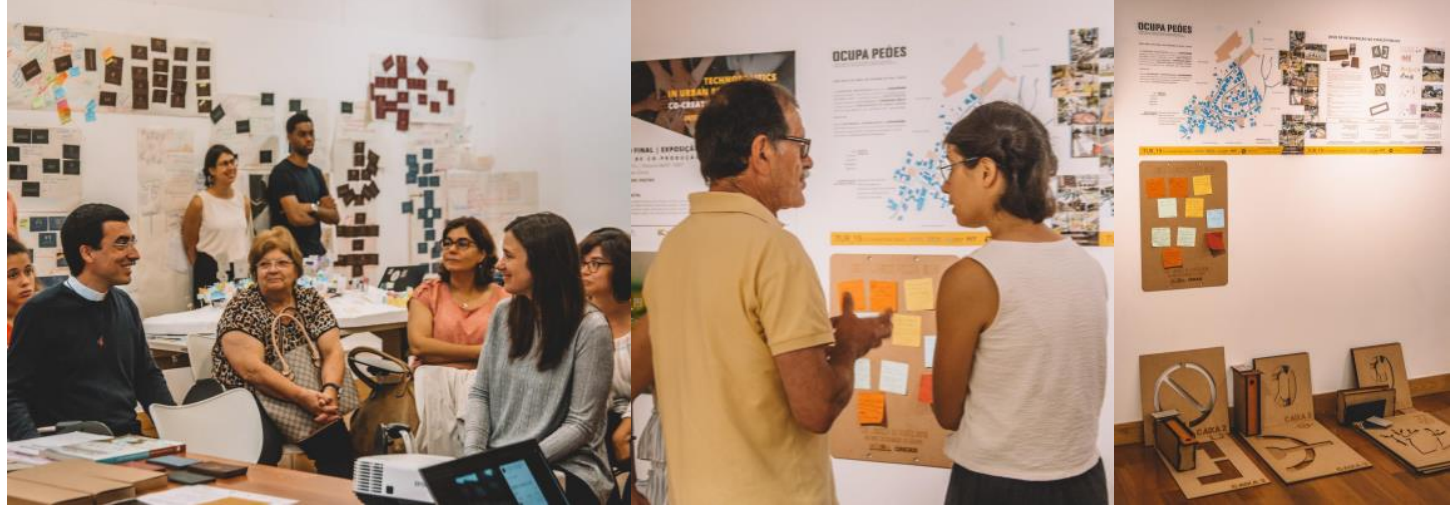

Fotos: Autoría propia. 


\section{Consideraciones finales}

Dado que el TUR forma parte de una experiencia de aprendizaje colaborativo en el ejercicio de diseñar la ciudad, una de las principales premisas del proyecto fue la creación de un entorno reflexivo que propiciara la reconfiguración de los límites de colaboración entre la universidad, la sociedad y los poderes públicos para la producción compartida de conocimiento. Para ello, era fundamental dar espacio a la investigación, pero también al diálogo y la experimentación con métodos y herramientas que propiciaran una dinámica de co-creación a favor de un desafío común en un contexto específico: el espacio público en el AUGI. Los resultados obtenidos permiten concluir que la metodología colaborativa adoptada ofrece potencial para trabajar en esta dirección a través de la intersección de la investigación, la educación, el conocimiento técnico y la ciudadanía, ofreciendo también oportunidades de aprendizaje para los diferentes actores involucrados.

En el ámbito político, es importante destacar la propuesta de LABTUR como una infraestructura que acerca el poder público a la ciudadanía, contribuyendo a un mejor entendimiento de las realidades mutuas. Según Freire (2020) normalmente, las instituciones públicas no permiten "la experimentación de prácticas o políticas, validaciones inestables o resultados provisionales, de los que depende la vida de muchos ciudadanos. Además, el sector público tiene otras barreras: una máquina burocrática tan necesaria como lenta" Freire (2020, pag.3), lo que puede ejemplificarse en el caso de la lentitud de los procesos de reconversión de la AUGI.

Resolver el problema de la falta de calidad en el espacio público requiere un trabajo conjunto entre la Municipalidad y los vecinos, lo que generalmente resulta en un largo camino de negociación, por las razones expuestas en el apartado 2.2. Por tanto, podemos concluir que es fundamental plantearse nuevos canales de escucha como LABTUR, que parten de la producción y la experimentación colaborativa.

Los instrumentos tradicionales que utilizan las instituciones públicas no parecen ser suficientes para resolver este problema. Así, en este trabajo defendemos la co-creación experimental como una forma de probar hipótesis sobre futuros alternativos. Tomando como ejemplo el caso del Bairro dos Peões, aunque observamos pocas tierras libres que pudieran ser transferidas al dominio público, la intervención temporal en la plaza generó una importante reflexión sobre el papel del espacio público en la calidad de vida de los niños en el vecindario. En consecuencia, algunos vecinos plantearon la posibilidad de dialogar con el propietario de una de estas tierras, para convertirla temporalmente en espacio para los niños. En el caso del Bairro Cabeço de Mouro, considerando la cantidad de terreno libre para construcción, este tipo de intervenciones temporales podrían influir en la toma de decisiones conjunta para el diseño del espacio público y fortalecer las relaciones vecinales, facilitando un acuerdo entre vecinos. Uno de los instrumentos de cogobernanza que podría ayudar a viabilizar este tipo de acciones sería el presupuesto participativo municipal, discutido en la fase de presentación de propuestas.

Las soluciones propuestas por los grupos y las discusiones resultantes presentaron oportunidades para la acción de la población y el gobierno, en una construcción más colaborativa y de diálogo en los territorios en cuestión. Sin embargo, la temporalidad de LABTUR imposibilita presentar soluciones definitivas. Sería necesario establecer un plan de acción conjunto entre los diferentes actores involucrados para promover desarrollos futuros. Este desafío conduce a nuevas preguntas y caminos de investigación. Una de las posibles consecuencias de la colaboración universidad-ciudadanía-poder público iniciada en LABTUR podría ser la promoción de un programa de formación enfocado a dotar a los vecinos de métodos y herramientas para el co-diseño, coproducción y cogobernanza de sus barrios. La acción continua en este sentido podría tener un impacto positivo en el ámbito disciplinar del proyecto urbano, tarea que normalmente es responsabilidad de un equipo contratado por la administración conjunta de propietarios/residentes.

ACE, 16 (46) CC BY-ND 3.0 ES | UPC Barcelona, España | LABTUR: Una contribución metodológica a las prácticas 20 de co-creación del espacio público. DOI: http://dx.doi.org/10.5821/ace.16.46.9893 
En el ámbito científico, hemos asistido a una mayor apertura de la ciencia y sus procesos, constatando una mayor colaboración en la producción científica (Parra et al, 2017). TUR es el resultado de esta necesidad de apertura y colaboración entre diferentes actores, con miras a transferir la ciencia a la sociedad y la sociedad a la ciencia. La metodología de laboratorio creada permite ampliar los espacios establecidos para la producción de conocimiento científico dentro de la producción colectiva de la ciudad. Sin embargo, sería necesario realizar una investigación más profunda sobre la colaboración entre universidad y ciudadanía, abriendo nuevos caminos para la ciencia ciudadana. En este sentido, la integración de los ciudadanos en grupos de trabajo sería importante para valorar los resultados de una colaboración más inmersiva y su impacto en las prácticas de co-creación del espacio urbano, a partir de relaciones más fluidas entre científico, ciudadano y autoridades públicas.

En cuanto a la dimensión tecnológica, las herramientas adoptadas permitieron ampliar las oportunidades de colaboración interna a través de la producción compartida, desde los datos (mapeo colectivo, red de actores y línea de tiempo) hasta los dibujos o su materialización (tecnologías de fabricación digital). Al mismo tiempo, la plataforma TUR nos permite brindar un alcance global, a través del intercambio de estos procesos y resultados, contribuyendo al objetivo principal de crear una metodología abierta y replicable. Sin embargo, se supone que la visualización de algunos datos no es de fácil acceso para los ciudadanos que no tienen un conocimiento avanzado sobre ellos. Sería necesario reflexionar sobre formas más accesibles e inclusivas. También sería importante explorar herramientas que permitan una mayor apropiación por parte de la población durante el proceso de co-creación.

Los dibujos de herramientas como las tarjetas de las masterclasses y el kit de ideación también se pusieron a disposición digitalmente en un formato de código abierto bajo una licencia creative commons $^{14}$, fomentando así el intercambio de conocimientos en el ámbito disciplinar y científico. En términos de desarrollos futuros, para aprovechar todo el potencial disponible, también sería importante explorar herramientas que permitan una mayor apropiación por parte de la población.

Y finalmente, en el contexto de la enseñanza de la arquitectura, LABTUR ofrece la oportunidad de expandir el aprendizaje a través de la colaboración de múltiples actores en contextos reales, poniendo en perspectiva el rol individual del arquitecto. En el libro Spatial Agency Other Ways Of Doing Architecture, los autores plantean la necesidad de una reforma en la enseñanza de la producción espacial, pasando de una lógica maestro-tutor a la del conocimiento mutuo. Esto implica un intercambio abierto de conocimientos y respeto por el conocimiento - disciplinario o no disciplinario - del otro (Awan et al, 2011). Una de las ideas fundamentales que encierra el aprendizaje colaborativo es que "el conocimiento se construye socialmente, en la interacción entre las personas y no traspasando el docente al alumno" (Torres et al, 2014, p.1). El formato de laboratorio urbano experimental permite al alumno desarrollar un pensamiento crítico sobre su papel en la producción espacial, a través del trabajo colaborativo en grupo, la estrecha relación con la comunidad local y la experimentación con diferentes herramientas que le permitan probar un lenguaje compartido. Poner la co-creación experimental en la práctica de la producción espacial provocará que ocurran varios cambios, cambiando la forma en que diseñamos, lo que diseñamos y para quién diseñamos. También ayudará a repensar las herramientas y métodos que se utilizarán. Como parte integral del proceso de co-creación, el arquitecto podrá explorar nuevas herramientas que puedan estimular la creatividad colectiva de todos los involucrados. Creemos que su potencial será aún más relevante en el futuro para abordar problemas urbanos complejos a medida que se combinen la producción espacial y la investigación.

\footnotetext{
${ }^{14}$ Creative Commons es una organización no gubernamental sin fines de lucro, dedicada a ampliar la cantidad de trabajos creativos disponibles a través de sus licencias que permiten copiar y compartir con menos restricciones que la tradicional "Todos los derechos reservados".
}

ACE, 16 (46) CC BY-ND 3.0 ES | UPC Barcelona, España | LABTUR: Una contribución metodológica a las prácticas 21 de co-creación del espacio público. DOI: http://dx.doi.org/10.5821/ace.16.46.9893 


\section{Agradecimientos}

Este trabajo está parcialmente financiado por fondos nacionales a través de FCT - Fundación para la Ciencia y la Tecnología, I.P., bajo el proyecto FCT UIDB / 04466/2020. Además, los autores desean agradecer al Instituto Universitario de Lisboa, DINAMIA'CET, ISTAR-IUL y al Ayuntamiento de Cascais por su apoyo. Y también a todos los participantes y organizadoras de TUR'19.

\section{Autoría}

La primera autora ha conceptualizado, diseñado y escrito la investigación. La segunda autora ha asesorado toda la investigación, contribuido en la realización del estudio y revisado el manuscrito para su publicación como artículo científico.

Conflicto de intereses: Las autoras declaran que no hay conflicto de intereses.

\section{Bibliografía}

Awan, N., Achneider, T., Till, J. (2011). Spatial Agency: Other Ways of doing architecture. New York, USA: Routledge.

Borja, J. (2011) Ciudades del mañana. Derecho a la ciudad y democracia real. Café de las ciudades. Recuperado de: www.cafedelasciudades;com;ar/urbanidad 108.htm

Borja, J. y Muxí, Z. (2003). El espacio público, ciudad y ciudadanía. Electra. Recuperado de: https://www.researchgate.net/profile/Zaida-Martinez/publication/31731154 El espacio publico ciu dad y ciudadania J Borja Z Muxi prol de O Bohigas/links/543fbcdo0cf2be1758cf9779/El-espaciopublico-ciudad-y-ciudadania-J-Borja-Z-Muxi-prol-de-O-Bohigas.pdf

Cardoso, A.; Paio, A.: Farias: A, Graça A. y L. Pomesano, (2019). Technopolitics in Urban Regeneration: Co-Creating Public Spaces. En Proceedings International Conference + Summer School 2019. Lisbon: ISCTE.

Castells, M. (2010). The Rise of the Network Society. 2 edicion. United Kingdom, UK: Blackwell Publishing Ltd.

Chase, J., Crawford, M., John K. (2000). Everyday Urbanism. New York, USA: The Monacelli Press

Claudel, M., y Ratti, C. (2016). The city of tomorrow. Yale University Press.

Concilio, G., Rizzo, F. (2016). Human Smart Cities. Rethinking the Interplay between Design and Planning. Springer.

CMC - Câmara Municipal de Cascais. (2011). Normas procedimentais para loteamentos e edificações inseridos em áreas urbanas de génese ilegal no concelho de cascais. Boletim Municipal. Recuperado de https://www.cascais.pt/sites/default/files/anexos/gerais/normas augi.pdf\%20\%20

DGT - Direção Geral do Território. (2020). Cidades sustentáveis 2020. Recuperado de http://www.dgterritorio.pt/ordenamento e cidades/cidades/cidades sustentaveis 2020/

De Lange, M., De Waal M., Ampatzidou, C.; Bouw, M., et al. (2015). The Hackable City: A Research manifesto and design toolkit. Amsterdam: Rose Leighton. Recuperado de https://issuu.com/thehackablecity/docs/hva the hackable city a research ma 
De Carlo, G. (1980). An Architecture of Participation. Perspecta: The Yale Journal, 17.

Ecosistema Urbano. (2014) Ecosistema Urbano gana el concurso para el Plan Maestro del Centro Histórico de Asunción. Sitio web del proyecto, Recuperado de: https://ecosistemaurbano.org/urbanismo/ecosistema-urbano-gana-el-concurso-para-el-planmaestro-del-centro-historico-de-asuncion/

Ecosistema Urbano. (2016) Plan maestro centro histórico asunción tomo 2.3 ASULAB. Recuperado de: https://issuu.com/ecosistemaurbano/docs/plan cha t2 p3 asulab

Ermacora, T., Bullivant, L. (2016). Recoded City: co-creating urban futures. New York, USA: Routledge.

Evans, J.; Karvonen, A.; y Raven, R. (2016). The experimental city. New York, USA: Routledge.

Freire, J. y Abad, D. (2020). Laboratorios de innovación ciudadana: Emergencia, modelo, formatos. DOI: $\underline{\text { https://doi.org/10.13140/RG.2.2.16198.91209 }}$

Friedmann, J. (1987). Planning in the public domain: From knowledge to action. Princeton, USA: University Press. DOI: https://doi.org/10.2307/j.ctv10crf8d

Friedmann, J. (1993) Toward a Non-Euclidian Mode of Planning. Journal of the American Planning Association. 482-484. DOI: https://doi.org/10.1080/01944369308975902

Fonseca, A. (2012). Laboratorios sociales y ciudadanos. LabSurlab + Co-operaciones. Medelín: Cooperaciones. Recuperado de https://ia802704.us.archive.org/34/items/labSurlabCo.Operaciones/LabsurlabCoOperaciones.pdf

Foth, M., Brynskov, M., Ojala, T. (eds). (2015). Citizen's right to the digital city: urban interfaces, activism, and placemaking, Springer.

Gehl, J. (2015). Cidades para pessoas. São Paulo, Brasil: Perspectiva.

Gehl, J., Svarre, B. (2015). How to Study Public Life. Washington, USA: Island Press.

Gershenfeld, N. (2005). Fab: the coming revolution on your desktop - from personal computers to personal fabrication. New York: Basic books.

Hamdi N. (2004) Small Change: About the Art of Practice and the Limits of Planning in Cities. London, UK: Earthscan

Harvey, D. (2012). Ciudades rebeldes. del derecho de la ciudad a la revolución urbana. Madrid, España: Ediciones Akal

Healey, P. (1997). Collaborative planning. Shaping places in fragmented societies, London, UK: Macmillan Press.

Jacobs, J. (1991) (2ee $)$ The death and life of great american cities. New York, USA: Random House

Jorge. S (2010) Qualicação do espaço público de loteamentos de génese ilegal na grande área metropolitana de Lisboa, en: Lúcia Bóg us et al. (or gs.). Da irregularidade fundiária urbana à regularização: análise comparativa Portugal-Brasil, S. Paulo: Educ, pp. 143-158.

ACE, 16 (46) CC BY-ND 3.0 ES | UPC Barcelona, España | LABTUR: Una contribución metodológica a las prácticas de co-creación del espacio público. DOI: http://dx.doi.org/10.5821/ace.16.46.9893 
Jorge, S. (2010). Da produção à qualificação do espaço urbano de génese ilegal: o caso da freguesia de Unhos. (Tesis de maestría). Lisboa: Faculdade de Arquitectura, Universidade Técnica de Lisboa. 5354 en Fernandes, J. O bairro na cidade: génese de vida social de bairro nas áreas urbanas de génese ilegal. (Tesis de maestría). Lisboa: Faculdade de Arquitectura, Universidade Técnica de Lisboa. 16-17.

Lafuente. A. (2005) los laboratorios ciudadanos y el anarchivo de los comunes. Recuperado de https://www.academia.edu/14834106/Los laboratorios ciudadanos y el anarchivo de los comun es

Lafuente. A. (2008). Laboratorio sin muros: inteligencia colectiva y comunidades de afectados. Centro de Ciencias Humanas y Sociales. Recuperado de http://digital.csic.es/bitstream/10261/2899/1/laborat orio sin muros.pdf

Lafuente, A. y Horrillo, P. (2016). Como hacer un prototipo. La Aventura de Aprender. Recuperado de http://laaventuradeaprender.intef.es/documents/10184/64755/Como-hacer-un-prototipo.pdf

Lafuente, A. Y Horrillo, P. (2017) Como hacer un mapeo colectivo. La Aventura de Aprender, Recuperado de http://laaventuradeaprender.intef.es/documents/10184/67475/Como-hacer-unmapeo-colectivo

Lefebvre, H. (1968). Le droit à la ville. Paris, éd. Anthropos.

Lefebvre, H. (2002[1970]) A Revolução Urbana. Belo Horizonte, Brasil: Editora UFMG.

Lefebvre, H. (1991) The Production of Space. Blackwell Publishing.

Lei no 91/95, d.r 1o serie-a no 203 (1995-09-02) pags. 5542-5550. Recuperado de https://dre.pt/web/guest/pesquisa/-/search/547220/details/normal?l=1

Manzini. E. (2015). Design, When Everybody designs. An introduction to design for social innovation. USA: MIT PRESS LTD.

Oliván, R.; Barriga, S, et al. (2018). Hacking inside black book Laaab. Recuperado de http://www.laaab.es/hackinginside/

Pagano, C. (2013). DIY Urbanism: Property and Process in Grassroots City Building. 97 Marq. L. Rev. 335. Recuperado de https://scholarship.law.marquette.edu/mulr/vol97/iss2/5/

Petrescu, D., Trogal, K. (2017). The social (re)production of architecture: politics, values and actions in contemporary practice. London, UK: Routledge.

Project for Public Spaces. d. What Makes a Successful Place? Recuperado de https://www.pps.org/article/grplacefeat

Puerari, E. Koning. J., Wirth, T. V., et al. (2018). Co-creation dynamics in Urban Living Labs. Sustainability, 10(6), 1893. DOI: https://doi.org/10.3390/su10061893

Raposo, I.; Bògús, L.; Pasternack, S. (2010), Da irregularidade Fundiária urbana à regularização: Análise comparativa Portugal- Brasil, São Paulo: EPUC-SP. Recuperado de http://www.gestual.fa.utl.pt/siteantigo/images/pdf/apresentacao livro Sao Paulo.pdf 
Salgueiro, T. (1998). Cidade pós-moderna: o espaço fragmentado. Revista Território, III(4) 39-53.

Sanders, E; Stappers, P. (2008). Co-creation and the new landscapes of design. Co-Design, 4:1, 5-18, DOI: https://doi.org/10.1080/15710880701875068

Sanoff, H. (2000). Community Participation Methods in Design and Planning. Landscape and Urban Planning. Wiley.

SEGIB. (2014). Laboratorios Ciudadanos: espacios para la innovación ciudadana. XXIV Cumbre Iberoamericana de jefas y jefes de estado y de gobierno Veracruz, 6 de diciembre.

Smith, N. (1984). Uneven development: nature, capital and the production of space. University of Georgia Press.

Torres, P., Irala, E. (2014) Aprendizagem colaborativa: teoria e prática. En Torres, P. (Ed) Complexidade: Redes e Conexões na Produção do Conhecimento (pp 61-93), Curitiba, Brasil: SENARPR.

UN - United Nations. (2016). Habitat III. The United Nation Conference on housing and sustainable urban development. Quito: UN. Recuperado de http://habitat3.org/the-new-urban-agenda

Zamenopoulos, T., Alexiou, K. (2018) Co-Design as Collaborative Research en Facer, K. y Dunleavy, K. (eds.) Connected Communities Foundation Series. Bristol: University of Bristol/ AHRC Connected Communities Programme. Recuperado de https://connected-communities.org/wpcontent/uploads/2018/07/Co-Design SP.pdf 